\title{
Resenha de estudos sobre o Executivo*
}

Argelina Maria Cheibub Figueiredo

\section{Introdução}

Esta resenha da literatura sobre o Executivo procura discutir o impacto dos diferentes sistemas de governo e sua capacidade em formular e implementar políticas públicas. Essa foi uma demanda da própria ENAP Escola Nacional de Administração Pública e se justifica, também, pela importância, em geral, atribuída ao impacto do sistema de governo no desempenho do Executivo e na natureza das políticas públicas.

Um estudo muito mais amplo e sistemático foi realizado para a ENAP sob a coordenação de Regis de Castro Andrade, em 1993. Esse estudo identificava uma situação de paralisia decisória e crise política decorrentes das características do sistema institucional brasileiro. Tal diagnóstico refletia a visão dominante no debate político que antecedeu a decisão a ser tomada no plebiscito de 1993 sobre o sistema de governo no Brasil. Encontrava também respaldo na discussão que se desenvolvia na comunidade acadêmica, tanto brasileira como internacional. Refletia, além disso, as dificuldades da transição para um sistema político plural e descentralizado intensamente presentes naquele momento.

Nos dez anos transcorridos desde esse estudo, houve um significativo desenvolvimento da pesquisa comparativa, com conseqüências relevantes para o foco analítico dos estudos sobre o funcionamento dos sistemas de governo. O estudo das instituições políticas brasileiras teve, também, um expressivo crescimento. Por sua vez, o sistema institucional brasileiro mostrou resistência, inesperada pelo diagnóstico anterior, a crises políticas e hoje apresenta inequívocos sinais de estabilidade. Por todas essas razões, é extremamente oportuna uma nova incursão nos estudos realizados nesse período.

Argelina Maria

Cheibub

Figueiredo é

PhD em

Ciência Política pela Universi-

dade de

Chicago; professora livre-docente do Departamento de Ciência Política da Unicamp; Pesquisadora Sênior do Cebrap; diretora do Centro de Estudos da Metrópole, Cepid-Fapesp/ Cebrap.

Contato: argelina@ uol.com.br 


\section{A literatura sobre o Executivo em diferentes sistemas de governo}

Esta resenha se orienta pela seguinte questão: quais fatores afetam a capacidade de o governo formular e implementar uma agenda política consistente que estabeleça uma clara hierarquia de prioridades? Em outras palavras, trata-se de identificar que fatores permitem ou impedem o governo de imprimir unidade a sua ação e de exercer uma efetiva função coordenadora das suas diversas áreas de atuação, tendo em vista as prioridades estabelecidas em sua agenda política.

Ainda que a capacidade de formular políticas esteja associada à capacidade de implementá-las, os fatores que as afetam não são os mesmos, de modo que essas duas capacidades podem ser tratadas de forma independente. Por exemplo, um governo pode ter alta capacidade de formulação, dispondo, para isso, de uma assessoria eficiente, mas uma baixa capacidade de implementação, não dispondo do apoio político ou do aparato administrativo necessário para implementar as políticas escolhidas. Por outro lado, um governo fragmentado, capturado por grupos de interesses, pode ter alta capacidade de implementação, mas baixa capacidade de definir uma agenda própria. Um governo efetivo deve ter alta capacidade em ambas as funções. O Quadro 1 resume as alternativas possíveis de diferentes tipos de governo a partir da combinação desses dois critérios.

\section{Quadro 1: Capacidade de formulação}

\begin{tabular}{|l|l|l|}
\hline & $\begin{array}{l}\text { Capacidade de } \\
\text { formulação Alta }\end{array}$ & $\begin{array}{l}\text { Capacidade de } \\
\text { formulação Baixa }\end{array}$ \\
\hline $\begin{array}{l}\text { Capacidade de } \\
\text { implementação Alta }\end{array}$ & Governo & Forte/Efetivo \\
\hline $\begin{array}{l}\text { Capacidade de } \\
\text { implementação Baixa }\end{array}$ & Governo Capturado & Governo Paralisado \\
\hline
\end{tabular}

Para se analisar a capacidade do governo em formular e implementar políticas públicas, três aspectos devem ser considerados. Em primeiro lugar, é necessário examinar a natureza da relação entre o Executivo e o Legislativo. O Legislativo desempenha papel essencial na formulação de políticas públicas, mas também tem influência na sua implementação. O segundo aspecto a ser examinado refere-se à estrutura do próprio Executivo, tendo como foco as relações entre a chefia do Executivo ou do governo e os ministros responsáveis pelas diversas áreas de atuação setorial do governo. E, em terceiro lugar, cabe analisar as relações entre o Executivo político, ou seja, a chefia de governo e seu gabinete e a 
burocracia. Com respeito a essa última, cabe distinguir, segundo Caldwell

(1993), a engrenagem herdada - o serviço público permanente - e a "engrenagem" criada - os funcionários nomeados e as assessorias políticas.

Do ponto de vista institucional, a literatura associa a capacidade do governo tanto na formulação quanto na implementação de políticas aos diferentes sistemas do governo. A literatura sobre governo comparado sustenta que variações no desempenho do governo podem ser explicadas pelas diferenças institucionais básicas que definem os sistemas parlamentarista e presidencialista de governo e que são, respectivamente, a fusão de poderes no parlamentarismo e a separação de poderes no presidencialismo. Essas características básicas determinariam o funcionamento e o desempenho dos governos, imprimindo a cada um deles uma dinâmica própria e resultados políticos correspondentes.

Moe e Caldwell argumentam: "Quando nações escolhem o sistema presidencialista ou parlamentarista, estão escolhendo um sistema completo, cujas propriedades têm origem endógena. (...) Cada forma institucional é um sistema completo (a full-blown system in the making). Esse sistema tem um código genético que programa os tipos de burocracia, as estruturas de liderança, os arranjos da burocracia e outras propriedades que conformam o governo. Ao adotar essa forma, as demais propriedades se seguem. Elas são escolhidas pelos participantes da política de escolha estrutural, mas as escolhas são previsíveis e altamente restritas. Elas simplesmente dão expressão ao código genético" (1994: 172 e 192).

Para esses autores, o sistema de governo geraria, portanto, uma burocracia marcadamente diferente em estrutura, performance e accountability. Outros aspectos do funcionamento e da performance do governo, tais como a sua capacidade de agir de forma coesa, de ter sucesso legislativo e de implementar políticas coerentes, necessariamente se seguiriam das características básicas desse sistema. ${ }^{1}$

A literatura comparada utiliza, em geral, dois modelos estilizados de sistemas de governo, baseados na fusão ou separação de poderes. No sistema parlamentarista, a efetividade do governo e a correspondência de suas políticas com as preferências do eleitorado são tidas como dadas. Há uma cadeia de transmissão que, partindo do eleitorado, passa pelo parlamento, é processada pelo gabinete e implementada pela burocracia, retornando ao eleitorado na forma de políticas públicas por ele apoiadas mediante o voto. Moreno, Crisp e Shugart (2003: 85-86) caracterizam essa cadeia como um processo de "hierarquias encadeadas" (nested hierarchies), uma cadeia única de relações entre agentes e mandatários (agents and principals), na qual cada entidade é o único agente de seu mandatário imediato. Os eleitores fazem apenas uma escolha: selecionam 
um candidato (ou uma lista) para representá-los no parlamento. Os partidos conformam o mecanismo de seleção de parlamentares e do gabinete que compartilham de suas preferências. O Executivo não tem nenhuma independência do Legislativo e nenhuma conexão direta com o eleitorado, é puro agente do parlamento e depende de sua maioria para sobreviver. Finalmente, a burocracia é um agente do gabinete, e mesmo os burocratas individuais que gozam de proteção no serviço público devem tão-somente implementar as ordens ministeriais. ${ }^{2}$

Em contraste a essa cadeia hierárquica única, no presidencialismo a literatura identifica vários pontos de tensão. A diferença fundamental é que o Executivo e o Legislativo são separados e independentes, tendo bases eleitorais próprias. Na formulação original de Linz, essa é uma fonte intrínseca de conflito entre os dois poderes e, conseqüentemente, um obstáculo para uma ação governamental unificada e responsiva a interesses mais gerais. Na versão de Moreno, Crisp e Shugart (2003: 87), apresentada em linguagem mais neutra e em maior sintonia com os desígnios dos pais fundadores do modelo de separação de poderes norteamericanos, esse desenho institucional requer "trocas horizontais" entre os dois poderes para a produção e implementação de políticas públicas. Em ambas as versões, a fonte de conflito é institucional, ou seja, independe da relação do presidente com a maioria representada no Legislativo. Quando o presidente tem maioria no parlamento, o presidencialismo tenderia a produzir governos capturados por grupos de interesses e pelo particularismo que caracteriza o Congresso, dados os seus vínculos eleitorais; dessa forma, o Executivo teria baixa capacidade de exercer sua função coordenadora e implementar políticas gerais. Quando o Executivo não conta com maioria no Legislativo, o resultado seria a paralisia decisória.

O segundo ponto de tensão no presidencialismo localiza-se na própria, ou seja, estrutura do governo: nas relações entre o presidente e o seu gabinete. A ausência de um sistema decisório coletivo afeta a capacidade do chefe do Executivo em imprimir unidade à ação governamental. Como afirma Neustadt (1960: 39), "os membros do gabinete são os inimigos naturais do presidente". Finalmente, o presidente e o Congresso competem pelo controle da burocracia em razão de suas diferentes bases eleitorais e da consequiente divergência sobre políticas públicas. Assim, o presidente cria uma burocracia presidencial paralela à burocracia pública permanente.

Os modelos estilizados de relações nos dois sistemas de governo, baseados nos traços institucionais básicos dos dois tipos de sistema de governo, podem ser representados como nos quadros a seguir: 


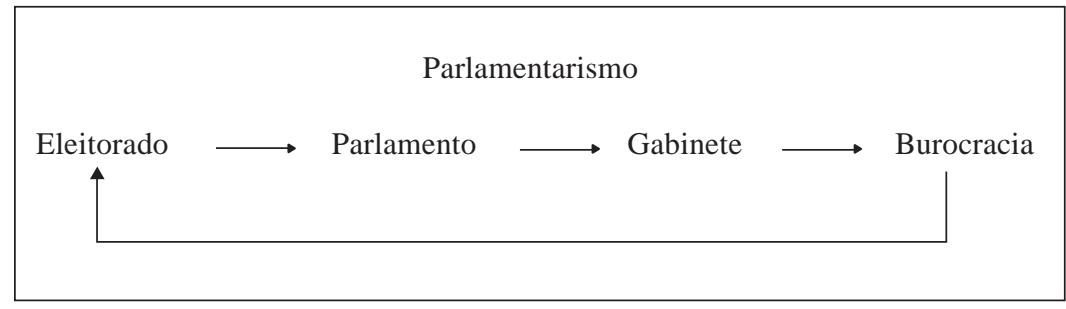

\section{Quadro 3: Presidencialismo}

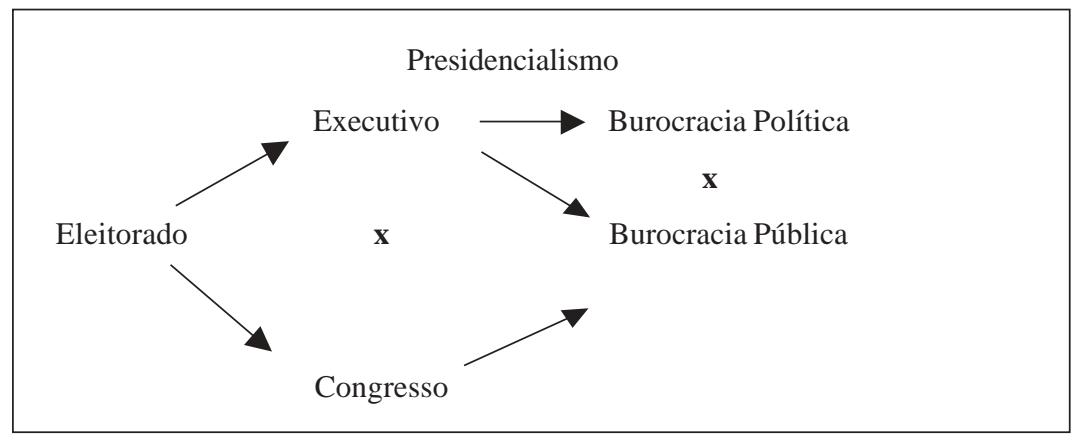

Na visão estilizada, a condição majoritária do governo é considerada uma consequiência natural do sistema parlamentarista. Como afirma Moe, outra característica distintiva do governo no parlamentarismo é que o Executivo e o Legislativo são controlados pelo partido majoritário (1990: 241). Essa condição, contudo, é negada pelos fatos.

Governo de partido majoritário não é a regra no parlamentarismo. Pelo contrário, uma pesquisa que considerou todos os governos do mundo mostrou que, no período entre 1946-1999, 43,2\% dos governos parlamentaristas tinham um partido majoritário no parlamento, enquanto em 55,5\% dos países presidencialistas, um partido tinha maioria no parlamento (Cheibub, Przeworski e Saiegh, 2004). Além disso, a probabilidade de o chefe do Executivo pertencer a um dos dois maiores partidos é praticamente a mesma nos dois sistemas de governo: 0,94 no parlamentarismo e 0,92 no presidencialismo (Cheibub, 2002).

Como a separação de poderes não garante a condição majoritária do presidente, esta é vista como forma de superação do conflito institucional e condição para o governo efetivo no sistema presidencialista. A realidade, porém, também se mostra bem mais complexa. Nos Estados Unidos, berço do presidencialismo e modelo de estabilidade política, a ausência de maioria no Congresso se tornou regra no pós-guerra: em $68,5 \%$ do tempo decorrido entre 1960-1995, ou seja, durante 24 anos em um período de 35 anos, 
um governo republicano teve de enfrentar uma maioria oposicionista em uma ou nas duas casas legislativas (Sundquist, 1988: 613).

No presidencialismo latino-americano, o multipartidarismo é visto como um problema adicional ao governo efetivo, dadas as dificuldades de formação de governos ou de coalizões majoritárias. No entanto, coalizões majoritárias formaram-se em $60 \%$ dos governos em países presidencialistas no período 1946-1999. Trata-se de uma proporção menor do que as coalizões majoritárias que se formaram no parlamentarismo (79\%), mas ainda assim governos de coalizão majoritários estão longe de constituir exceção no presidencialismo (Cheibub, Przeworski e Saiegh, 2004).

Além disso, o mecanismo que no sistema parlamentarista mantém o Executivo responsável perante o Legislativo, ou seja, a dissolução do gabinete e a convocação de eleições para a formação de um novo governo não funcionam exatamente de acordo com a teoria. Um estudo de 21 democracias parlamentaristas no período 1946-1995 mostra que mudanças de governo no parlamentarismo não são produto de eleições. Nesse período, as seguintes mudanças no governo ocorreram sem a convocação de eleições: mudança de primeiro-ministro em 56\% dos casos; mudança no partido do primeiro-ministro (38\%); mudança na composição partidária do gabinete (46\%); e mudança no maior partido da coalizão de governo (24\%) (Cheibub, 2002).

A diversidade de condições dos governos democráticos no século 20 mostra a distância entre os modelos estilizados de sistemas de governo, elaborados com base em seus traços institucionais básicos e o funcionamento desses governos. Mostra, ainda, que esses modelos, tomados como "pacotes completos", têm pouco a oferecer para a compreensão das condições institucionais de funcionamento de um governo efetivo.

Em meados dos anos 1980, Rockman (1986: 134) sugeria a necessidade de orientar os estudos sobre o Executivo em duas direções. A primeira seria no sentido de realizar análises comparativas, "tanto das capacidades formais como do comportamento do Executivo em sistemas similares e não similares", ou seja, comparar a estrutura e o funcionamento do Executivo em diferentes sistemas de governo. A segunda consistiria em aumentar a integração dos estudos sobre o Executivo (especialmente sobre a Presidência norte-americana) com o acervo de conhecimentos sobre a política e a governança nos sistemas democráticos.

Com efeito, pesquisas comparativas sistemáticas e empiricamente fundamentadas tiveram expressivo crescimento nos anos posteriores à resenha de Rockman. Um importante resultado dessas pesquisas foi mostrar a enorme diversidade no interior de cada um dos sistemas de governo, não só em suas regras formais como no seu funcionamento de fato. Esses 
achados têm contribuído para estimular pesquisas comparativas entre sistemas, assim como para a elaboração de modelos analíticos que aumentem a nossa compreensão sobre o funcionamento do governo. No entanto, persiste, ainda, uma enorme separação nos estudos sobre o Executivo nos dois sistemas de governo. Uma exceção é o próprio Rockman que, juntamente com Weaver, organiza uma coletânea de estudos de caso, mostrando que diferenças na capacidade de governo não decorrem da simples distinção entre o sistema parlamentarista e os sistemas de separação de poderes. Weaver e Rockman argumentam que não só essas diferenças importam, mas também as estruturas de formulação de políticas decorrentes de diferentes padrões de formação de governo, além de outras instituições do sistema político, como o federalismo, o judiciário e a burocracia (1993).

Quanto à segunda linha sugerida por Rockman, pode-se dizer que passos importantes foram dados no sentido de integrar o estudo do Executivo com os estudos sobre o governo e o sistema institucional mais amplo. A principal contribuição nessa direção vem da corrente neoinstitucionalista da teoria da escolha racional, mas a literatura institucionalista ainda atribui peso significativo ao sistema de governo na determinação de seu funcionamento e de seu desempenho - premissa que é incorporada em algumas das mais influentes análises recentes. Os modelos de análise mais elaborados ainda mantêm como referência teórica básica os traços que distinguem os dois sistemas de governo.

As comparações entre sistemas tendem a se concentrar nos seus dois modelos típicos: os Estados Unidos e a Inglaterra. Ainda são raros os estudos que tratam comparativamente de países com diferentes sistemas, e quando o fazem também tendem a enfatizar as diferenças que decorrem das características constitucionais básicas de cada um desses sistemas. Com isso, não requer negar a existência de incentivos decorrentes da fusão ou separação de poderes, mas mostrar que os traços institucionais básicos de cada um desses sistemas não podem ser considerados condição suficiente para determinar a capacidade de governo.

Por essa razão, aqui serão analisados separadamente os estudos sobre o Executivo no parlamentarismo e presidencialismo, enfatizando os resultados das pesquisas que apontam as variações no funcionamento de cada um dos sistemas de governo. Procura-se mostrar que cada uma das relações que, nesses modelos estilizados, são dadas como parte integrante de um modelo de governo efetivo pode ser questionada com base em estudos recentes, fundamentados em pesquisas empíricas sistemáticas. Por outro lado, procuro mostrar que novos modelos de análise questionam alguns dos pressupostos básicos dessas interpretações, buscando incorporar novas variáveis explicativas. 
Dentre essas variáveis, os recursos institucionais de que dispõe o chefe de governo, especialmente seus poderes de agenda, têm uma importância significativa no funcionamento do governo e na sua capacidade de formular e implementar políticas. A existência desses poderes independe do sistema de governo adotado e, muitas vezes, tem influência no desenvolvimento da capacidade de governo ao longo da história de diferentes países. Esses estudos mostram que o uso de poderes institucionais de agenda determinou o sucesso de estratégias de centralização do processo decisório que tiveram impacto significativo sobre a capacidade do governo de coordenar sua própria estrutura interna e de obter o apoio do Legislativo e a aquiescência da burocracia para a implementação de sua agenda política.

\section{Estudos sobre o Executivo no Parlamentarismo}

Em uma resenha publicada em 1975, King argumenta que falar da relação entre Executivo e Legislativo só faz sentido em um sistema de separação de poderes, pois no sistema parlamentarista a fusão de poderes é definidora do sistema de governo. A partir daí identifica três tipos de relações a serem analisadas no sistema parlamentarista: entre o governo e sua base parlamentar (backbench supporters); entre o governo e a oposição; e entre o governo e os parlamentares (backbenchers) de todos os partidos. Ressalva, porém, que nos governos majoritários do tipo britânico, o parlamento não pode ser descrito como uma legislatura, sendo, portanto, inadequado afirmar que o Legislativo influencia o Executivo. Nesse caso, valem apenas os dois primeiros tipos de relação: entre o governo e sua base parlamentar, que aprova suas propostas políticas, e entre o governo e a oposição, que as rejeita.

Quando o governo é minoritário ou de coalizão, a relação do governo com os parlamentares de todos os partidos (terceiro tipo) assume importância. Nessas situações, argumenta King, os representantes dos partidos opositores percebem que o que os une como parlamentares (ou defensores de políticas específicas ou de qualquer outro tipo de medida) é mais importante do que aquilo que os divide como membros de partidos opositores. Ainda, segundo King, esse tipo de relação é geralmente tomado como típico do presidencialismo norte-americano, em que os partidos são fracos e os eleitos estabelecem vínculos pessoais com o seu eleitorado, mas nos governos minoritários corresponde ao paradigma tradicional de relações Executivo-Legislativo. O "modo de governo" minoritário e/ou de coalizão - forma, como King caracteriza, o modelo predominante na Europa 
continental - é em tudo semelhante ao modelo majoritário, exceto pelo

fato de que o governo torna-se dependente de dois ou mais partidos, os quais podem formar um governo de coalizão ou permanecer fora do governo, mas nas votações apóiam o governo minoritário que se forma. Emerge, então, uma diferença entre os partidos no governo e os partidos no parlamento: governos podem colher votos em partidos que não estão no governo (King, 1975: 235-237).

Antecipando uma diferença que mais tarde será ressaltada pelos estudos de caso na Europa continental, King faz uma distinção entre o que chama de "modo majoritário de governo" e "modo de governo minoritário ou de coalizão". Essa diferença não é pouco significativa, pois o número de partidos envolvidos altera substancialmente as relações relevantes nesse "modo de governo", produzindo importantes efeitos no seu funcionamento. Nesses casos, também torna-se relevante, como ressalta King, a relação entre os líderes de todos os partidos que formam a coalizão ou apóiam o governo minoritário de um lado e a relação entre esses líderes e suas bancadas, de outro.

Passa a fazer sentido, então, falar em relações Executivo-Legislativo no parlamentarismo. Como argumenta King, essas relações devem ser descritas mais especificamente como relações inter e intrapartidárias, que se expressam por meio dos procedimentos legislativos. O efeito mais imediato desse tipo de relação é que, no caso do governo majoritário a pressão dos parlamentares (backbenchers) tende a ocorrer a portas fechadas, ou seja, nas reuniões do gabinete, ao passo que nos governos minoritários e de coalizão, tem lugar em público (King, 1975: 237). Os exemplos a que o autor se refere são a França da IV República e a Alemanha, ou seja, governos de coalizão. Ele não menciona estudos sobre governos minoritários, em virtude da escassez de pesquisas sistemáticas sobre o assunto no momento daquela resenha.

Apesar do pioneirismo da distinção feita por King, uma classificação mais consistente deve distinguir governos majoritários de governos minoritários, sendo que cada qual pode ser de partido único ou de coalizão. Estudos posteriores postulam diferentes lógicas e resultados em termos de políticas públicas em governos minoritários (Strom, 1990) e em governos de coalizão majoritários (Laver e Schofield, 1990). Cabe ressaltar, ainda, que o autor desconsidera inteiramente a existência de governos de coalizão no presidencialismo, mantendo os Estados Unidos como um caso único de governo de separação de poderes.

A análise de King reflete a visão clássica dos estudos sobre o Executivo no parlamentarismo: a de que o gabinete é um agente perfeito do parlamento. Como se aponta adiante, estudos recentes questionam essa pressuposição e partem do suposto inverso, ou seja, o de que o gabinete 
tem um papel independente na determinação dos resultados de políticas públicas.

Em 1988, em um volume especial do European Journal of Political Research, intitulado "Cabinet Structure and Decision-Making Processes in Western Europe", Jean Blondel, com base nos estudos de caso que o compõe, sugere uma agenda de pesquisa que é inovadora em dois sentidos: ao enfatizar a diversidade no interior do sistema de governo parlamentarista e ao dirigir o foco da pesquisa para a estrutura do processo decisório no interior do gabinete.

$\mathrm{Na}$ introdução do volume, escrita em co-autoria com Jean-Louis Thiebault, Blondel observa que a predominância de estudos sobre o caso britânico sugere a existência de um modelo único de governo de gabinete. Ressalta assim que, para se alcançar uma compreensão mais geral dessa forma de governo, é necessário expandir a base empírica das análises sobre o parlamentarismo e definir uma agenda de pesquisa verdadeiramente comparativa. Ao sumariar as principais conclusões dos estudos de caso contidos naquela publicação, os organizadores destacam a enorme diversidade encontrada, no que diz respeito às várias dimensões contempladas naqueles estudos. Ressaltam que seus resultados divergem do que até então era tomado como padrão de governo de gabinete: o modelo britânico. Dessa forma, o que na visão tradicional era dado como suposto, passa a ser objeto de investigação.

Tendo como foco os países da Europa continental, os estudos realizados analisam os seguintes aspectos do funcionamento dos sistemas parlamentaristas: a importância dos partidos, o papel dos ministros individualmente, a extensão do poder do primeiro-ministro e o papel coletivo do gabinete, por meio de suas reuniões. Esses estudos mostram que, em alguns países, o papel individual dos ministros é bem diferente do papel que desempenham no modelo majoritário. Ao contrário do padrão britânico de amadorismo dos ministros e dependência da burocracia, em alguns desses países os ministros detêm considerável especialização em suas áreas de responsabilidade, bem como gozam de grande autonomia. O que emerge desses estudos é um modelo de influência individual dos ministros bem mais heterogêneo, que contrasta com o padrão tomado como característico do governo de gabinete. Estudos posteriores atribuirão o crescimento da importância individual do ministro - mesmo no caso britânico à especialização que passa a ser exigida para o exercício desse cargo.

Um outro aspecto revelado por esses estudos é a grande variação na autoridade do primeiro-ministro entre países e em um mesmo país ao longo de sua história. No caso da Alemanha, por exemplo, onde o chanceler é poderoso, apontam-se variações importantes no período pós-guerra. 
de governo, concluem que, no geral, a posição institucional dos primeiros-

ministros se fortaleceu. Nem todos os premiês detêm os amplos poderes de nomeação e de agenda que o primeiro-ministro britânico sempre deteve, mas seus poderes têm se ampliado.

Um estudo posterior sobre as chefias do Executivo na Europa Ocidental confirma os achados desses estudos de caso e apresenta um quadro comparativo que vale a pena reproduzir (King, 1994: 153):

\section{Quadro 4: Grau de influência do primeiro-ministro no governo em países selecionados}

\begin{tabular}{|l|l|l|}
\hline Alta & Média & Baixa \\
\hline Alemanha & Áustria & Itália \\
Grã-Bretanha & Bélgica & Países Baixos \\
Grécia & Dinamarca & Noruega \\
Irlanda & Suécia & \\
Portugal & & \\
Espanha & & \\
\hline
\end{tabular}

Como mostra o Quadro 4, em países com diferentes "modos de governo", como a Grã-Bretanha e os países não-majoritários incluídos na primeira coluna, os primeiros-ministros têm alto grau de influência no governo. Por outro lado, a influência do premier em países multipartidários também é bastante variável: nesses países encontramos ministros com alta, média e baixa influência. Portanto, a composição partidária do governo pouco contribui para explicar esse aspecto da organização do governo. Isso indica que a influência do primeiro-ministro provavelmente decorre menos da situação partidária dos governos e mais de seus poderes institucionais, que, como já indicado, têm se ampliado.

Por fim, os estudos apresentados por Blondel colocam em xeque um outro elemento básico do modelo clássico de parlamentarismo: o papel do conselho de ministros como órgão deliberativo coletivo. Mostra-se que muitas vezes a influência desse conselho é limitada pela autonomia dos ministros em suas próprias jurisdições e pelo próprio poder do primeiroministro. Estudos posteriores reforçam esse achado. Um detalhado estudo empírico mostra que, na Áustria, a relevância política das reuniões de gabinete depende do tipo de governo. Em governos de coalizão, essas reuniões são consideradas um locus pouco importante na discussão de questões relevantes para 93\% dos ex-ministros entrevistados. Nos governos de partido único, ao contrário, são consideradas importantes por $64 \%$ dos entrevistados. Os ministros desempenham um papel importante em sua própria área de jurisdição e têm baixa participação em matérias relacionadas a outros departamentos, o que denota, também, a menor 
importância do gabinete como uma instância coletiva de tomada de decisões (Muller, 1994: 17-18). Mesmo na Grã-Bretanha, o gabinete vem perdendo poder de decisão para o primeiro-ministro e para os ministros responsáveis por departamentos específicos. Como argumenta Norton, longe de ter um governo de gabinete, a Grã-Bretanha tem hoje uma forma de governo ministerial (1991: 211).

Em trabalho não muito posterior ao volume também editado por Blondel, Laver e Schofield (1990), os autores fazem uma avaliação mais positiva dos resultados alcançados pelos estudos de caso dos países europeus - que eles identificam como a "tradição de estudos da política européia”. Para esses autores, tal tradição de pesquisa empírica de casos nacionais já teria acumulado um significativo volume de informações e achados sobre a experiência européia de governos de coalizão, o qual deveria ser integrado a uma outra tradição também voltada para o estudo de coalizões políticas: a da teoria dos jogos. Os autores de Multiparty Government definem como seu objeto de estudo específico "a interação entre os poderes Executivo e Legislativo nas ocasiões em que nenhum partido obtém maioria no parlamento" e fazem o primeiro esforço sistemático e teoricamente elaborado de estudo dos governos de coalizão (Laver e Schofield, 1990: 2). Para tanto, lançam mão de todo o arsenal de conhecimento empírico acumulado pelos estudos da política européia e do instrumental analítico da teoria dos jogos sem recorrer à formalização característica dessa última. Ao elaborar os elementos básicos de seu modelo de análise, partem, no entanto, de pressupostos opostos aos que dão fundamento aos modelos clássicos das teorias de coalizão, também na tradição da teoria dos jogos.

O livro apresenta uma revisão das evidências empíricas disponíveis em vários estudos de caso, visando avaliar a plausibilidade de muitos pressupostos das visões tradicionais da teoria dos jogos e, dessa forma, justificar a violação de alguns deles. Parte desses aspectos será desenvolvida e integrada em esquemas de análise mais elaborados e formalizados em trabalhos posteriores dos próprios autores, ou de outros da escola institucional da teoria da escolha racional.

No que diz respeito aos atores, Laver e Schofield colocam em xeque o pressuposto do partido como um ator unitário, assumido pelas teorias de coalizão. No que diz respeito aos interesses (stakes) em jogo na formação dos governos, criticam essas teorias por se concentrarem na luta pelo controle partidário do gabinete no momento de sua constituição. A participação no governo é vista como um prêmio em si e por si só. Ao contrário dessa concepção, argumentam que o interesse dos partidos e de seus membros em políticas públicas específicas e em seus resultados é uma dimensão importante, que deve ser incorporada nos modelos de análise de governos 
parlamentaristas. Isso significa que o jogo não se limita apenas a uma luta entre partidos pelo controle do gabinete, mas trata-se também de uma luta intrapartidária pela formulação e implementação de políticas públicas específicas.

Incorporando ainda resultados de estudos de casos, os autores criticam também a visão tradicional de como o jogo é vencido. Rejeitam a "idéia de que 'ganhar' significa ter uma maioria de cadeiras na legislatura", e argumentam que "é necessário trabalhar com a idéia de um governo "viável', e não apenas de um governo majoritário" (Laver e Schofield, 1990: 12). Por fim, criticam o foco quase exclusivo dos estudos de coalizão no processo que culmina com a formação do governo. Enfatizam que é necessário estudar o processo posterior à formação das coalizões de governo, a forma de funcionamento do governo e especialmente a questão da duração do gabinete. Para eles, essa mudança de foco tem uma importância prática que merece ser enfatizada aqui, em razão das analogias que podem ser estabelecidas com o debate institucional no Brasil. Eles observam que "aqueles que atacam o governo de coalizão (frequientemente os mesmos que também criticam sistemas eleitorais baseados na representação proporcional) tratam as coalizões como (inerentemente) instáveis. Um exame ainda que superficial das evidências mostra que isto não é verdade" (Laver e Schofield, 1990: 12).

Isso significa que o foco de análise passa do processo de formação do gabinete para o funcionamento de fato do governo. Ao se estabelecer isso, fica implícito que as condições que levam ao sucesso da formação de um governo não são as mesmas que levam ao sucesso de sua manutenção. Ou seja, o sucesso do governo não acontece está dado pela sua origem, já que a formação de um governo majoritário não é condição suficiente para o seu funcionamento.

Como observam Laver e Shepsle em uma resenha mais recente, as teorias em geral não se preocupavam com o que os governos faziam depois de subir ao poder. As teorias da escolha racional sobre eleições e competição partidária dão pouca atenção ao papel do gabinete no processo de competição partidária. Algumas teorias sobre formação de governo pressupõem que o jogo acaba no momento em que os payoffs são distribuídos, ou seja, quando os partidos assumem o controle dos ministérios. Outras teorias sobre formação de governo pressupõem que os governos implementam tudo o que foi prometido no processo de negociação para a constituição do governo (Laver e Shepsle, 1994: 129-131).

Em suma, mediante uma crítica mais elaborada teoricamente, mas que já estava presente nas observações de Blondel, esses autores questionam a usual suposição de que, uma vez que o gabinete é formado com uma certa composição partidária que lhe garante maioria no parlamento - ao qual deve responsabilidade e do qual pode receber um voto de 
desconfiança-, as políticas a serem implementadas seguem-se automaticamente desse arranjo. Propõem, assim, que as atenções se voltem para um novo conjunto de questões que dizem respeito não às características básicas do sistema de governo, mas aos mecanismos institucionais que regulam o processo de tomada de decisões, seja no interior do gabinete, seja no parlamento.

Laver e Shepsle (1994: 134) resumem as questões que devem orientar a elaboração de respostas sistemáticas ao problema do governo de gabinete da seguinte forma: “1) Quais são os procedimentos para propor e votar moções de confiança e de desconfiança no governo? O governo pode controlar esses procedimentos? O Legislativo pode propor como quiser tais moções? 2) O Legislativo pode impor unilateralmente decisões sobre políticas públicas a um gabinete contrário a essas políticas? O Legislativo pode impor unilateralmente decisões sobre políticas públicas a um ministro contrário a essas políticas? 3) Em que medida o gabinete controla a agenda substantiva do Legislativo?"

Respostas a essas questões requerem comparações em dimensões pouco investigadas sistematicamente e que, como argumentarei mais adiante, tornam possível ultrapassar a barreira entre sistemas de governos. Entre essas dimensões, assume importância fundamental a dos poderes de agenda do Executivo.

Em dois trabalhos posteriores, Laver e Shepsle dão continuidade a esta agenda de pesquisa. O primeiro reúne um conjunto de estudos de caso, visando testar a plausibilidade do que chamam de "abordagem de alocação ministerial" (portfolio-allocation approach). Segundo essa abordagem, os ministros têm autonomia em suas áreas setoriais e, portanto, a alocação de pastas a um determinado partido ou indivíduo tem consequiências em termos de políticas públicas (Laver e Shepsle, 1994).

Para testar essa forma, distinguem inicialmente dois modelos de processo decisório no gabinete: o de governo burocrático e o de governo legislativo. No governo burocrático, nem a composição partidária do Legislativo nem o Executivo tem impacto na política pública. No governo legislativo, todas as políticas são decididas pelo Legislativo e o papel do gabinete seria de implementação mecânica. Em seguida, partindo do pressuposto de que nem a burocracia nem o Legislativo determinam as políticas públicas, nas quais, ao contrário, o Executivo joga um papel crucial, e levando em conta que os ministros individualmente são constrangidos pelo primeiro-ministro, por suas organizações partidárias, pelo gabinete coletivamente ou por nenhum desses atores, distinguem quatro modelos de governo: "de primeiro-ministro", "partidário", "de gabinete" e "ministerial".

Por essas denominações pode-se deduzir o grau de influência de cada um dos atores nesses quatro modelos de governo. Vale ressaltar, 
porém, que a dinâmica do modelo de governo partidário, tal como apresentada neste trabalho, reforça as observações de King quanto ao funcionamento dos "modos de governo" majoritário e multipartidário. No governo majoritário as disputas partidárias são dirimidas no âmbito do gabinete, de modo que é difícil, mas também irrelevante, verificar se quem decide sobre políticas é o partido ou o gabinete. No caso de governos em que nenhum partido controla a maioria, a política partidária interna e o processo decisório no gabinete são duas atividades distintas, mas que frequientemente se impõem uma sobre a outra (Laver e Shepsle, 1994: 5-8).

Resumindo as principais evidências coletadas nos estudos de caso, esses autores verificam que a composição partidária do gabinete afeta a política governamental; que importantes políticas públicas são formuladas pelos ministros responsáveis por departamentos ou áreas de políticas específicas; que os ministros têm mais importância do que a burocracia de suas áreas; e que os ministros de outras áreas têm pouca importância nas áreas de jurisdição de cada ministério. Esses resultados são considerados como evidência contrária aos modelos de governo legislativo e burocrático e indicadores de dominância do governo ministerial. Conforme argumentam, "há um forte grau de departamentalização na formulação e implementação de políticas públicas, e os ministros, enquanto chefes de departamentos/jurisdições, desempenham um importante papel nesse processo" (Laver e Shepsle, 1994: 307). ${ }^{3}$

Em seu mais recente livro, Making and breaking governments, em que elaboram teoricamente e testam de forma mais sistemática esse modelo, Laver e Shepsle afirmam que a visão das teorias convencionais de coalizões se esfacela em face do indubitavelmente firme controle que o governo exerce sobre o Legislativo. Segundo eles, "uma legislatura, por certo, constrói e destrói governos, mas não governa um país" (Laver e Shepsle, 1996: 12).

\section{A literatura sobre o Executivo no Presidencialismo}

Os estudos sobre o Executivo, no sistema de governo presidencialista, concentram-se em duas correntes vinculadas a diferentes áreas de conhecimento, nas quais se organiza a ciência política norte-americana. Os poucos estudos da ciência política européia sobre a Presidência também se voltam exclusivamente para o estudo do caso norte-americano. Da mesma forma, análises mais recentes sobre o semipresidencialismo na Europa limitam suas comparações ao caso norte-americano.

A primeira corrente dessa literatura constitui uma das áreas de estudos sobre a Presidência, vinculada à denominada American Politics. 
Como tal, compreende um extenso volume de trabalhos com um único foco empírico nos Estados Unidos, desconsiderando inteiramente a predominância do presidencialismo na América Latina. A área de American Politics inclui também uma subárea de estudos legislativos, centrada mais nos aspectos organizacionais e políticos do Congresso norte-americano, do que nas suas relações com o Executivo.

Dessa forma, o governo é tratado por dois campos distintos de estudos - um sobre o Legislativo e outro sobre a Presidência - que se desenvolveram de forma independente, com metodologias e abordagens teóricas distintas. Os estudos sobre a Presidência nos EUA enfatizaram seus aspectos individuais, explorando os diferentes estilos de liderança, baseados em detalhados estudos de caso. Nos estudos legislativos, ao contrário, a análise institucional encontrou campo fértil e se desenvolveu a partir de pressupostos da teoria da escolha racional e por meio do uso de métodos formais e da análise estatística. Só recentemente a revolução neoinstitucionalista chegou aos estudos sobre a Presidência, redirecionando o foco original para o aparato organizacional erguido em torno do presidente e enfatizando a institucionalização da Presidência. Dentro dessa abordagem, os esforços analíticos de maior fôlego buscaram uma ponte entre esses dois campos de conhecimento, procurando oferecer uma interpretação mais integrada do governo no sistema presidencialista. Esses modelos, porém, ainda mantêm foco empírico exclusivo na Presidência norte-americana e têm como única referência comparativa o modelo estilizado de parlamentarismo europeu, mais particularmente o britânico.

A segunda corrente da literatura norte-americana sobre Executivo no presidencialismo vincula-se à área de estudos sobre a América Latina. Compreende também a produção latino-americana, em geral voltada para a análise isolada dos países. Esses estudos foram fortemente influenciados pela literatura sobre transição política, especialmente os trabalhos de Juan Linz. Partindo de uma crítica a Linz, o livro de Shugart e Carey Presidents and Assemblies (1992) torna-se um marco na literatura sobre o presidencialismo. Trata-se do primeiro esforço de comparação abrangente de países com presidentes eleitos diretamente. A principal contribuição desse livro foi mostrar a diversidade no interior do presidencialismo, tendo como principal fator de diferenciação os poderes legislativos do Executivo.

Essas duas correntes de estudo sobre o presidencialismo - a que se dedica ao estudo da Presidência norte-americana e a que se dedica ao estudo do presidencialismo na América Latina - ainda guardam considerável distância entre si. Para se ter uma idéia da falta de comunicação entre elas, em uma coletânea de 1993 que reuniu os mais importantes estudiosos do Executivo para um balanço da área, King observa que uma das dificuldades intelectuais para o estudo comparativo da 
Presidência americana é o fato de que ela é única. Segundo ele, "o que torna os Estados Unidos peculiar é que o presidente americano é ao mesmo tempo chefe de governo, chefe de Estado, chefe único do Executivo, comandante-em-chefe e uma figura deliberadamente separada do Legislativo nacional" (1993: 419).

Nas seções que se seguem, serão tratadas separadamente cada uma dessas correntes.

\section{A literatura sobre a Presidência nos Estados Unidos}

Antes de se poder falar da existência de uma área de estudos sobre a Presidência nos Estados Unidos, predominava entre os cientistas políticos a visão de que em um sistema de poderes dispersos o partido seria o único mecanismo capaz de induzir alguma forma de coordenação e harmonia entre os poderes e, em conseqüência, torná-los efetivos. Nas palavras de Burns:

"Se não há uma maneira de harmonizar os órgãos separados do governo, uma ação sustentada e efetiva pode ser impossível. É essa função vital de integração que o partido deve cumprir. Operando em ambas as casas do Congresso e por meio de suas comissões, tendo como seu chefe o ocupante da Casa Branca (...), o partido majoritário é o instrumento perfeito para exercer o mandato popular" (1949: 45).

Essa visão foi elevada à condição de teoria dominante na forma de um relatório apresentado pelo Committe on Political Parties na reunião anual da American Political Science Association de 1950. O relatório não só expressava essa visão do partido como um "indispensável instrumento de governo", como propunha uma série de reformas no sentido de tornar os partidos políticos norte-americanos mais organizados, disciplinados e "mais responsáveis" (apud Sundquist, 1988: 619). As críticas que se seguiram a esse relatório não contestavam a noção de "governo responsável", mas o realismo das propostas nele defendidas, dadas as dificuldades de mudar a constituição americana e a limitada capacidade dos partidos americanos de desempenhar de forma adequada essa função unificadora. Sem descartar o papel dos partidos, a teoria foi modificada para incorporar a liderança do presidente da República como o mecanismo capaz de garantir a disciplina partidária. Nessa reformulação da teoria original do "responsible party government”, a função unificadora passa a ser possível porque os membros do partido do presidente no Congresso o reconhecem não apenas como o chefe do Executivo, mas também como líder do partido, escolhido pelo eleitorado nacional. Assim, o partido do 
presidente necessariamente deve ter maioria no Congresso. Além disso, o presidente detém todos os recursos do Poder Executivo para ajudá-lo a desenvolver programas coordenados e de interesse geral (Sundquist, 1988: 118-21).

Não muito tempo depois, Burns, em livro intitulado The Deadlock of Democracy (1963), apontando as dificuldades enfrentadas pelo presidente Kennedy para enfrentar as grandes questões nacionais, constata que a maioria partidária no Congresso não garante um governo efetivo. Em resposta aos desiludidos, a Realpolitik emerge na ciência política americana, na corrente pluralista que, sob a liderança de Robert Dahl e Charles Lindblom, passa a ser o paradigma dominante na disciplina. De acordo com esse paradigma, no sistema americano o processo decisório não pode ser abrangente, permitindo aos presidentes fazer mudanças apenas incrementais (Caldwell, 1993: 386).

Richard Neustadt, em seu Presidential Power, publicado em 1960, incorpora a revolução behavioralista ao estudo da Presidência (Moe, 1993: 338) e busca na personalidade, estilo e habilidades do presidente os fundamentos do poder presidencial. A referência partidária desaparece na análise de Neustadt. Ele mostra como os presidentes foram desenvolvendo e organizando o seu poder em um contexto institucional adverso ao exercício de sua liderança. Seu ponto de partida, portanto, é institucional: no sistema constitucional de separação de poderes, o presidente é destituído de poderes formais para exercer sua liderança. Sendo assim, os fundamentos do poder presidencial devem ser buscados nos seus aspectos informais e nas características pessoais do presidente. De acordo com o paradigma pluralista, o poder presidencial depende dos requisitos do cargo e dos recursos de que dispõe o seu ocupante para exercer influência sobre a formulação e implementação de políticas públicas.

Para o autor, a influência efetiva do presidente americano "deriva de três fontes relacionadas: as primeiras são as vantagens inerentes ao seu cargo, com as quais persuade outros homens que o que ele quer deles é o que as suas próprias responsabilidades requerem que eles façam. Em segundo lugar, deriva das expectativas desses outros homens a respeito de sua habilidade e vontade de usar essas vantagens. Em terceiro lugar, decorre das estimativas a respeito de como o público vê o presidente e como o seu próprio público o verá se eles fizerem o que o presidente quer. Em suma, o poder do presidente é produto de sua posição privilegiada no governo, juntamente com sua reputação na comunidade de Washington e de seu prestígio externo" (Neustadt, 1960: 179). Para Neustadt, portanto, diante de seus fracos poderes institucionais, o presidente dispõe de duas estratégias básicas para obter o apoio do Congresso e da burocracia: a persuasão e a barganha. Para tanto, dispõe de dois recursos: sua reputação 
e seu prestígio público. Como observa Moe, a explicação de Neustadt

para a Presidência pessoal é institucional. Contudo, o foco de sua análise está na ação e não no contexto. As forças que movem a política presidencial e determinam o seu sucesso são pessoais.

O exercício de uma liderança forte requer uma personalidade extraordinária, vontade política e habilidades especiais. Só um indivíduo dotado dessas qualidades pode explorar as oportunidades para maximizar sua influência no processo decisório e imprimir sua marca nas políticas públicas. A capacidade de realizar pessoalmente várias das funções para as quais o presidente dispõe de um significativo aparato organizacional é condição sine qua non para obter resultados em seu próprio favor. As funções de persuasão e barganha não podem ser transferidas. O presidente é também o único capaz de zelar pela sua reputação e prestígio. Dessa forma, "precisa ser seu próprio especialista, seu próprio assessor, seu diretor de inteligência - o que significa que precisa ser altamente habilidoso na arte da política, ser altamente bem informado sobre as políticas públicas, as estratégias e as personalidades, ser altamente experiente nos caminhos do mundo político e entusiasticamente envolvido nas trocas miúdas do cotidiano da política (horse-trading)" (Moe, 1993: 339). Como afirma Neustadt, "a presidência não é lugar para amadores" (1960: 180).

A influência de Neustadt na literatura sobre a Presidência foi significativa e duradoura. A marca dessa influência revela-se na ênfase dada ao estilo de liderança e à contribuição individual de cada presidente, para a criação e expansão do aparato organizacional que passou a fazer parte da Presidência. Moe considera uma ironia que a versão da Presidência pessoal de Neustadt tenha exercido tanta influência precisamente quando essa tornava-se altamente institucionalizada. Para ele, "a marca da Presidência moderna é o seu crescimento e desenvolvimento como uma instituição. Compreende centenas de indivíduos em cargos e funções que formam uma rede organizacional altamente diferenciada, cuja estrutura básica ganhou substancial estabilidade e uniformidade ao longo de diferentes administrações" (1993: 340). Os fundamentos do poder presidencial não são pessoais, mas institucionais. A chave para o sucesso presidencial está na sua capacidade institucional, "a qual, apropriadamente desenhada, capacitará um pequeno exército de pessoas a desempenhar uma ação efetiva em nome do presidente" (1993: 242).

A revolução institucionalista é assim introduzida nos estudos sobre a Presidência. O trabalho desenvolvido por Moe, que inclui uma série de artigos publicados a partir de meados dos anos 80, é uma das mais importantes contribuições para a elaboração de uma teoria integrada das instituições políticas, visando compreender o funcionamento do governo e o controle político da burocracia. Na construção dessa teoria, Moe faz 
uma crítica contundente à teoria da "dominância congressual", sustentada pela corrente institucionalista da escolha racional que se desenvolveu no âmbito da subárea de estudos legislativos. ${ }^{4} \mathrm{O}$ principal alvo dessa crítica é seu foco exclusivo nas instituições congressuais e eleitorais para explicar o funcionamento do sistema de governo. Concordando com os pressupostos institucionalistas das teorias congressuais, Moe refuta o argumento substantivo básico de que o Congresso controla a burocracia. Segundo ele, essa conclusão baseia-se exclusivametne nas instituições legislativas e eleitorais e ignora os fundamentos e a lógica do controle político, bem como a própria burocracia.

Ele argumenta que a compreensão do controle político e do comportamento da burocracia em um sistema democrático de governo requer uma teoria baseada em uma visão coerente do sistema institucional como um todo, incorporando, além do Congresso, as motivações e a lógica de comportamento dos presidentes, das cortes, dos grupos de interesse e das próprias agências burocráticas. Além disso, faz uma crítica das concepções de instituições e de política presentes na teoria da dominância congressual, assim como de sua dependência da metodologia das teorias da public choice. Segundo ele, essa teoria concebe as instituições essencialmente como meios para mitigar problemas de ação coletiva e possibilitar a cooperação mediante ganhos obtidos pela troca política. A política, por sua vez, é vista em termos de escolhas legislativas expressas por meio do voto e como uma extensão da economia.

Em contraste a essa visão, Moe resgata e ressalta o caráter coercitivo e redistributivo das instituições políticas: "a política diz respeito fundamentalmente ao exercício da autoridade pública e à luta para obter controle sobre ela" e a "peculiaridade da autoridade é que aquele que a exerce tem o direito de dizer aos demais o que fazer, queiram eles ou não". Ou seja, a economia envolve trocas voluntárias, enquanto a política é inerentemente coercitiva (Moe, 1990: 221-22). Para mostrar a importância dos aspectos coercitivos e redistributivos das instituições políticas, Moe traça um paralelo com a mera transposição da lógica econômica da troca voluntária e dos ganhos daí advindos para o campo da política: "Quando duas pessoas pobres e uma rica formam uma polity governada pela regra da maioria, a pessoa rica está em apuros. E isso ocorre não porque a regra da maioria é instável. Nem por que as três pessoas terão dificuldade de realizar ganhos por meio de trocas. Ela está em apuros porque as outras duas usarão a autoridade pública para tomar o seu dinheiro. A autoridade pública lhes dá o direito de melhorar sua situação a expensas da pessoa rica. Suas decisões são legítimas e compulsórias" (Moe, 1990: 221).

A introdução do conceito de autoridade pública inverte a relação privada entre mandatário e agente. Primeiro, porque é o agente que tem 
autoridade efetiva, e não o mandatário; em segundo lugar, porque a relação

é essencialmente involuntária e compulsória (Moe, 1990: 233). Uma consequiência imediata do fato de que as instituições políticas são instâncias de exercício da autoridade pública é que os seus ocupantes usam seu mandato temporário para desenhar novas estruturas e impor essas estruturas à polity como um todo. Essas estruturas são veículos por meio dos quais os ocupantes de posições públicas procuram perseguir seus interesses. Algumas estruturas podem servir, apenas, para administrar programas que oferecem benefícios aos vencedores; outras podem extrair recursos ou impor ajustes na conduta dos perdedores; outras, ainda, podem impor novos limites à maneira como o jogo político será jogado no futuro, conferindo aos vencedores de hoje vantagens sobre os seus oponentes em lutas futuras para exercer a autoridade pública (Moe, 1990: 222).

Moe argumenta, portanto, que o melhor lugar para se entender como surgem e se configuram as instituições políticas não é o Congresso. Em primeiro lugar, é necessário distinguir os atores públicos ou "estatais", que tomam decisões "autoritativas" (authoritative decisions), ou seja, revestidas de autoridade, e os atores não-governamentais ou sociais (grupos de interesses e constituencies) (Moe, 1990: 229). Os primeiros, por sua vez, dividem-se em dois tipos: eleitos, presidentes e legisladores, e não-eleitos, a burocracia pública. Dessa forma, uma interpretação do desenvolvimento de instituições de governo e das suas conseqüências para a influência desses atores na formulação e implementação de políticas públicas deve ser construída com base nas motivações, preferências, recursos institucionais, estratégias, coalizões e escolhas de cada um desses atores. E, para Moe, os presidentes são centrais nesse modelo. Isso, por três razões.

Em primeiro lugar, porque os poderes do presidente ultrapassam o seu papel formal de vetar legislação. Presidentes têm poderes de agenda. Como chefes do Executivo, exercem um conjunto de poderes formais, para administrar e controlar a burocracia pública. Os presidentes são assim jogadores importantes em si, pois em questões relacionadas à estrutura detêm o poder de agir unilateralmente. Enquanto o Congresso precisa passar por um "difícil" processo legislativo para criar uma agência governamental, o presidente pode criar unilateralmente uma nova estrutura administrativa que atenda a seus interesses na implementação de políticas públicas. Esses poderes tiveram um aumento substancial depois do New Deal e são exercidos por meio dos seguintes órgãos: o Office of Management of the Budget, o White House Office, o National Security Council e as várias unidades do Executive Office of the President (Moe, 1990: 236).

Em segundo lugar, a centralidade dos presidentes decorre da natureza dos seus interesses. Em contraste com o Congresso, altamente 
responsivo aos estreitos interesses dos distritos eleitorais e dos Estados, portanto, de grupos específicos, o presidente tem uma base heterogênea e nacional que lhe permite resistir a apelos específicos e o leva a pensar em termos mais amplos sobre os problemas e interesses sociais, preocupando-se fundamentalmente com problemas de governança. Ainda em contraste com os legisladores, presidentes são vistos pelo público como responsáveis por praticamente todos os aspectos do desempenho do governo, que colocam em jogo sua popularidade, reputação e legado histórico. Conscientes desse fato, buscam construir e organizar uma capacidade institucional para o governo efetivo. São, portanto, os únicos atores motivados para a criação de sistemas burocráticos unificados, coordenados e centralmente dirigidos. Os presidentes visam criar uma burocracia controlada de cima, enquanto os legisladores, dadas a fragmentação e a descentralização do Congresso, preferem uma burocracia organizada por partes, sem sentido organizacional global.

O terceiro fator que confere centralidade e importância teórica aos presidentes é a sua autonomia. Esta autonomia também decorre de sua base eleitoral ampla, heterogênea e competitiva, e ainda do suposto de que o presidente age "como um time", não enfrentando problemas de ação coletiva. Para Moe, "o presidente é mais independente dos grupos organizados que animam a política legislativa". A autonomia do presidente também é incrementada pela baixa prioridade que atribui à reeleição especialmente no segundo mandato, ressalva o autor. Presidentes têm mais autonomia para definir sua própria visão da agenda pública, e sua preocupação com o governo efetivo os leva a criar estruturas centralizadas que lhes dêem controle da burocracia pública (Moe, 1990: 237).

Por tudo isso, os grupos de interesse organizados têm bases racionais para temer mais os presidentes do que os legisladores, de forma que na busca de seus interesses procurarão criar estruturas para limitar o controle presidencial. Assim, argumenta Moe, quando são levadas em consideração as motivações e preferências do presidente, as instituições políticas que emergem do jogo político assumem características distintas. As demandas sobre os legisladores e os presidentes são diferentes. Presidentes usam sua influência no processo legislativo para engendrar estruturas burocráticas presidenciais distintas, e fora do processo legislativo tomam ações unilaterais para impor essas estruturas sobre tudo o que foi criado pelo processo legislativo.

O resultado desse processo, conclui o autor, é um "pesadelo estrutural”: "A burocracia pública americana é uma confusão organizacional. Mas há uma explicação racional para isso. Não é uma confusão misteriosa, mas uma confusão que pode ser entendida, levando-se em consideração os poderes, os interesses e as estratégias de todos os jogadores e não apenas dos legisladores" (Moe, 1990: 238). Para Moe, "a dinâmica central 
do sistema institucional americano deriva dessa tensão entre presidentes que visam controle e os jogadores do Legislativo e dos grupos de interesse que procuram demarcar seus restritos territórios" (Moe, 1993: 373).

O "pesadelo estrutural" americano resulta da separação de poderes (Moe e Caldwell, 1994). Há uma diferença estrutural básica entre a burocracia americana e a britânica: a primeira é altamente formalizada e regulada por uma gama de mecanismos estruturais que limitam o poder discricionário dos órgãos públicos e dos seus funcionários e os tornam pouco responsivos, ao passo que a segunda é menos formalizada, mais discricionária, coerente e sujeita ao controle hierárquico. No sistema de separação de poderes, a formalização torna-se uma estratégia extremamente atrativa de proteção de interesses que é perseguida por todos os atores: grupos de interesse e legisladores acumulam todos os tipos de restrições formais para proteger "suas" agências dos presidentes; estes, por sua vez, impõem seus próprios mecanismos burocráticos em contraposição aos que foram instituídos pelo Congresso. Todos procuram proteção, e as estruturas formais a fornecem (Moe, 1990: 240). Nesse sistema é difícil alterar o status quo: regras formais garantem que ganhos obtidos no presente persistirão no futuro. Moe não explica, porém, por que os mesmos problemas que impedem o Legislativo de alterar as regras formais não o impedem de aprová-las.

Esse diagnóstico da burocracia americana é quase consensual. $\mathrm{O}$ importante livro de Hugh Heclo, A Government of Strangers, mostra que o funcionalismo público nos Estados Unidos é excluído do centro do Executivo, ou seja, a Presidência, e que o alto funcionalismo é constituído por um sistema duplo, que compreende uma burocracia pública formal e uma tecnocracia política informal. Para o autor, isso ocorre por razões históricas: o funcionalismo público americano se desenvolveu muito depois da Constituição, não integrando, portanto, a cultura constitucional, e não teve raízes num governo monárquico ou aristocrático. Além disso, desenvolveu-se depois da consolidação de partidos políticos de massa e da organização de interesses, quando o Legislativo e não o presidente detinha o poder de nomeação. ${ }^{5}$ De todo modo, parece exagerado o peso atribuído por Moe ao sistema de governo. Para dar apenas um exemplo contrário, no parlamentarismo japonês o primeiro-ministro consegue superar o presidente americano nas nomeações políticas, que ali chegam a trinta mil (King, 1994: 435).

A explicação de Moe, para os males que assolam a burocracia americana, apóia-se, na verdade, em alguns dos pressupostos sobre as motivações e os interesses dos legisladores e dos grupos organizados que ele critica na teoria da dominância congressual. Na coalizão que ele diz se estabelecer entre os legisladores e os grupos de interesse para fatiar o governo, reedita-se a versão do "triângulo de ferro" sustentada pela 
corrente distributivista: organizados em comissões especializadas que controlam determinadas políticas e recursos orçamentários, os legisladores atendem aos interesses de suas estreitas bases eleitorais e das agências burocráticas especializadas, que buscam expandir seus orçamentos.

Por outro lado, a sua argumentação sobre a autonomia do Executivo e o postulado de que este atende necessariamente ao interesse geral carecem de fundamento teórico e de base empírica sólida. Em uma crítica mais geral ao sistema de fiscalização administrativa do Executivo, West e Cooper (1990) apresentam uma evidência empírica que contraria esse pressuposto e questionam, com base nesse exemplo, o seu fundamento teórico. Trata-se de um "sistema de fiscalização executiva" criado pelo presidente Reagan em 1981, por meio da Executive Order no 12.291, que obriga os órgãos públicos a submeter todas as suas propostas e regulamentos finais ao Office of Management and Budget. West e Cooper afirmam que, após sete anos de vigência desse sistema, poucos contestariam que a intervenção do Executivo foi muito freqüentemente movida por considerações políticas. Essas considerações, porém, não foram motivadas por preocupações majoritárias e amplas, e sim por interesses de grupos que procuravam bloquear regulamentações nas áreas de saúde, segurança, consumo e meio ambiente, que são usualmente vistos como interesses que movem a ação congressual. Os autores observam que esse caso é interessante para discutir o problema da base eleitoral do presidente, porque na verdade o viés pro-business da fiscalização executiva exercida durante o mandato de Reagan não deixa de ser consistente com o clima conservador que o levou ao poder (West e Cooper, 1990: 590, 595-96).

Esse exemplo leva-nos a uma outra observação sobre o modelo elaborado por Moe, no qual ele exclui qualquer consideração de natureza partidária ou ideológica. Isso fica claro na idéia de que o presidente não tem interesse em sua reeleição. Para Moe, o presidente é o equivalente funcional do partido majoritário no parlamentarismo, com uma diferença fundamental enquanto os partidos são organizações com um horizonte de tempo infinito, pois esperam repetir o jogo político muitas vezes, os presidentes são indivíduos que param de jogar depois do segundo mandato. Essa diferença determinaria a estratégia do presidente: ele quer ficar na história, e para isso basta implementar políticas durante o seu mandato. Moe toma, por suposto, que o presidente não se interessa pela continuidade do seu partido no governo, nem pela continuidade de políticas públicas, cuja implementação tenha sido eventualmente bem-sucedida. Dessa forma, o seu modelo incorpora componentes tanto do pluralismo incremental como da concepção personalista da Presidência. Isso transparece na seguinte caracterização que faz da Presidência moderna: 
"A presidência hoje é completamente diferente do que foi na época de Roosevelt. As raízes da mudança estão no ativismo progressivista de Theodore Roosevelt e Woodrow Wilson, assim como na criação do Bureau of the Budget em 1921. Mas sua real transformação foi iniciada por Franklin Roosevelt, que ao engendrar o New Deal e liderar a nação na guerra revolucionou as expectativas públicas sobre o cargo presidencial. Daquele ponto em diante todos os presidentes passaram a ser vistos como responsáveis pela solução de todos os problemas sociais e como aqueles que, por meio de liderança legislativa e do controle do Executivo, seriam capazes de exercer uma ação efetiva. Como os meios de que dispunham eram muito reduzidos para corresponder a essas expectativas, eles responderam da melhor maneira que podiam, desenvolvendo de forma incremental a sua capacidade institucional para governar. O resultado foi uma trajetória de mudança na qual, ao longo de décadas, o processo decisório tornouse mais centralizado na organização da Casa Branca e a burocracia tornou-se mais politizada (ou mais 'presidencializada'), por meio de nomeações e do controle de cima para baixo" (Moe, 1993: 341).

Tendo também como objeto o crescimento do Poder Executivo no desenvolvimento do sistema institucional americano, Whittington e Carpenter desenvolvem uma abordagem bastante semelhante à de Moe, mas introduzem no seu modelo o papel do presidente como líder partidário e formador de coalizões, recuperando a idéia do "responsible party government'. Como líder nacional de seu partido, o presidente exerce controle sobre recursos partidários, especialmente fundos de campanha, sendo também responsável "por manter a coerência ideológica do partido e preservar o significado que identifica o rótulo partidário, o que traz vantagens eleitorais para todos os seus membros". Além disso, o caráter nacional de sua representação aumenta sua capacidade de formar coalizões que agreguem a diversidade de interesses de grupos e de regiões (Whittington e Carpenter, 2003: 500-01).

Em seus trabalhos mais recentes, em co-autoria com Howell, Moe volta-se para o estudo da ação unilateral do Executivo, especialmente por meio das executive orders, que são vistas como instrumentos não só de controle sobre a burocracia, mas também de expansão da capacidade de o presidente legislar sobre políticas substantivas. As executive orders são diretivas presidenciais que solicitam ou autorizam ações no interior do Poder Executivo. Por meio delas o presidente pode organizar e regulamentar o Executivo sem a aprovação do Congresso, (equivalem ao decreto de regulamentação no Brasil, mas aqui alguns desses atos administrativos do presidente, como a criação de agências e reorganização ministerial, requerem a apresentação de projetos de lei). 
Vários estudos mostram que nos Estados Unidos as executive orders são usadas de forma bem mais ampla do que a sua definição formal. Segundo Mayer, presidentes têm usado as executive orders para "estabelecer políticas, reorganizar agências do Poder Executivo, alterar processos administrativos e regulatórios, afetar a forma como a legislação é interpretada e implementada e empreender qualquer tipo de ação permitida nos limites de sua autoridade legal e constitucional" (Mayer, 2000: 445). Apesar de reconhecer a amplitude das decisões tomadas por meio desse instrumento, Mayer entende que essa ação se restringe aos limites definidos pelas normas constitucionais e legais. Ele observa, porém, que estudos jurídicos reconhecem que "o papel legislativo do presidente é substancial, persistente e em muitos casos alarmantes" (Fisher, 1993: 59, apud Mayer, 2000: 447). Refere-se, também, a estudos que criticam as cortes de justiça por não interferirem nas ações presidenciais, mantendo executive orders que "na melhor das hipóteses são constitucionalmente ambíguas (...) ou emitidas sem uma base legal específica" (Fleischman e Aufuses, 1976: 5, apud Mayer, 2000: 448).

Moe e Howell argumentam, porém, que o poder de ação unilateral do Executivo não deriva de sua natureza formal, como ocorre com o poder de veto e de nomeações, mas da força e da flexibilidade da ambigüidade do contrato que o estabelece. Como os limites de seu uso não são definidos constitucional ou legalmente, os presidentes podem, e têm fortes incentivos para, explorar essa ambigüidade e expandir seus poderes (Moe e Howell, 1999a: 134-35).

Os estudos são unânimes em mostrar que medidas importantes são tomadas por meio desse instrumento. Em seu livro Power without Persuasion, cujo título é uma alusão à tese de Neustadt, Howell (2003) afirma que as principais mudanças em políticas da era moderna nos Estados Unidos tiveram origem na ação unilateral do Executivo, mencionando os seguintes exemplos: as ordens de Roosevelt para a implementação do National Industrial Reconstruction Act durante o New Deal; as ordens de Truman, para forçar compromissos de lealdade no funcionalismo federal; os esforços de Kennedy, para controlar a violência racial no Alabama; e os atos de Johnson, para estabelecer as primeiras medidas de ação afirmativa.

Vale a pena listar outros exemplos de políticas substantivas, instituídas por esse instrumento: criação do Executive Office of the Presidency; confinamento de japoneses na II Guerra Mundial; medidas anti-segracionistas nas Forças Armadas; exigência de implementação de políticas de ação afirmativa por parte dos contratantes do governo; exigência de que regulamentações governamentais sejam justificadas por análises de custo-benefício; compra da Louisiana; anexação do Texas; libertação dos escravos (Emancipation Proclamation); doação de terras públicas para sistemas de parque nacional; iniciativas de ação afirmativa; 
criação de grandes agências, como Food and Drug Administration e Peace Corps; revogação do tratado de responsabilidades para com Taiwan (Mayer, 2000: 445-46; Moe e Howell, 1999a: 133-34).

Moe e Howell mostram, pois, que o presidente norte-americano, apesar de ser considerado institucionalmente fraco, detém "capacidade formal de ação unilateral e, portanto, de legislar por conta própria”. Eles observam que os presidentes americanos sempre tiveram esse poder, mas a estratégia de ação unilateral cresceu e se tornou mais central na Presidência moderna. O resultado é "uma mudança lenta, mas duradoura do equilíbrio institucional em favor do presidente" (Moe e Howell, 1990b: 851). Não entrarei aqui nos detalhes do modelo teórico elaborado por esses autores para explicar o papel legislativo do presidente que, na verdade, é uma adaptação do modelo anterior. Apresentarei apenas alguns resultados a que chegaram, procurando manter a própria terminologia que utilizam e fazendo a tradução mais literal possível (Moe e Howell, 1999a: 154-77).

1) Os presidentes tiraram vantagens da ambigüidade da Constituição e asseguraram direitos expandidos de ação presidencial. Usaram seus poderes unilaterais para fazer grandes mudanças, e mesmo mudanças históricas, na política nacional, por meio de sua autoridade exclusiva.

2) Houve um aumento do uso de executive orders em questões importantes no período recente. Os presidentes teriam suas maiores oportunidades de agir unilateralmente em períodos de guerra e crise econômica, mas a emergência da era moderna, com mudanças na urbanização, industrialização, imigração e desenvolvimento econômico, gerou novas demandas e incentivos, a que os presidentes responderam com a afirmação de sua liderança e a busca de meios para tomar iniciativas unilaterais. Nesse sentido, a primeira presidência moderna não foi a de Franklin Roosevelt, mas a de Theodore Roosevelt, que, sem exigências de guerra, foi o primeiro a adotar uma liderança agressiva para resolver os problemas da nação. T. Roosevelt argumentava que presidentes têm de tomar iniciativa para promover os interesses da nação, a menos que explicitamente proibido pela Constituição. Nessa sua visão, portanto, a ambigüidade legal convidaria os presidentes a preencher o vazio e assumir a política nacional.

Nesse relato, Moe deixa claro o pressuposto de que o presidente é, por excelência, o promotor do interesse nacional. Mayer discorda dessa visão e afirma, ao contrário, que algumas executive orders "podem não ter impacto amplo, mas ainda assim são extraordinariamente importantes para grupos de interesse específicos e constituencies" (Mayer, 2000: 446). O exemplo dado por West e Cooper sobre o sistema de fiscalização executiva implantado por Reagan, citado acima, vai na mesma direção.

3) O Congresso, de certa forma, pavimentou o caminho para o exercício cada vez maior dos poderes presidenciais de ação unilateral. 
Ao contrário do que afirma a visão dominante sobre a relação ExecutivoLegislativo nos Estados Unidos, o Congresso sempre teve uma inclinação a delegar poderes ao Executivo em várias áreas de políticas públicas. Não que o Congresso dê carta branca ao Executivo: ocorre que a própria proliferação de leis teve o efeito de criar um arcabouço elástico de legislação que, pelas inconsistências e conflitos que contém, acaba por dar um amplo espaço de manobra ao Executivo para perseguir sua própria agenda.

Em apoio ao argumento da delegação, Moe e Howell referem-se ao livro de Epstein e O'Halloran (1999). Mas estes mostram, na verdade, que o Congresso delega ao Executivo em áreas específicas de políticas, especialmente as mais complexas e de maior conteúdo informacional, conservando de forma ciumenta sua própria autoridade em áreas de taxação e gastos. Os legisladores delegam também em certas áreas de políticas distributivas em que estariam obviamente interessados, em face dos benefícios que trariam para suas bases eleitorais. Por fim, esses autores concluem que há maior delegação quando o Executivo tem maioria partidária no Congresso, ou seja, o Congresso delega menos em períodos de governo dividido.

4) O Congresso raramente empreende uma ação efetiva para reverter o uso desses instrumentos: de mil executive orders emitidas no período 1973-1997, o Congresso tentou reverter apenas 37, a maioria delas "morreu" nas comissões e apenas uma foi transformada em lei. Além disso, o Congresso raramente tentou limitar esse poder, e quando o fez, não foi bem-sucedido. Apesar de todo o conflito durante as administrações Bush e Reagan, o Congresso mostrou-se incapaz de derrubar a "infame" executive order $n^{\circ} 11.291$ de 1981, que fortaleceu o processo de fiscalização executiva sobre toda forma de regulamentação feita pelas agências públicas.

5) Em matéria de política externa, o Executivo faz uso de outro instrumento, os executive agreements, originalmente criados para firmar acordos internacionais de menor importância que, ao contrário dos tratados, não precisariam passar pelo Congresso. Moe e Howell (1999a) apontam que após a II Guerra Mundial a proporção de agreements em relação aos tratados chega a $93 \%$ e nas décadas seguintes permanece em torno de $98 \%$. Por meio desse instrumento, importantes medidas foram tomadas sem necessidade de aprovação do Congresso. Um exemplo de acordo importante para estabelecer organizações internacionais é a criação do Fundo Monetário Internacional (Moe e Howell, 1999a: 163).

Em resumo, os estudos mais recentes sobre a Presidência nos Estados Unidos mostram uma clara tendência de fortalecimento institucional do presidente em um país tido como o caso paradigmático de 
presidencialismo e onde um presidente fraco não tem poderes formais de apresentar propostas de legislação ao Congresso. Esse fortalecimento dá-se não só pelo seu controle sobre a burocracia, mas também pela sua influência nas políticas públicas, para tanto, como um dos principais mecanismos a sua capacidade de agir unilateralmente por meio de instrumentos de agenda setting.

\section{Estudos sobre o Presidencialimo na América Latina}

A literatura sobre o presidencialismo na América Latina foi fortemente influenciada pelos trabalhos de Juan Linz. Para Linz e seus seguidores, em um debate que é bastante conhecido no Brasil, a independência entre os poderes Executivo e Legislativo gera uma relação conflituosa entre eles, com efeitos diretos sobre a capacidade de governo e a estabilidade do regime político. De acordo com essa visão, no parlamentarismo a maioria forma o governo e a falta de apoio ao gabinete leva à sua queda ou à sua dissolução do parlamento com o objetivo de formar nova maioria. No presidencialismo, ao contrário, o presidente constitui a maioria, e como seu mandato é fixo, os casos de impasse entre o Executivo e o Legislativo geram um imobilismo que leva à ineficácia do governo e, em geral, à ruptura do regime político. Em suma, a instabilidade política na América Latina tem raízes nas características básicas do sistema de governo adotado pelos países no continente.

O livro Presidents and Assemblies de Shugart e Carey (1992) representa um ponto de inflexão nessa literatura e será o foco desta seção. Além de mostrar a variação no interior do presidencialismo, esse estudo introduz uma nova variável que tem adquirido importância cada vez maior no estudo comparativo dos sistemas de governo: os poderes legislativos do Executivo. No entanto, como se tentará mostrar no resumo que se segue, esse estudo ainda retém aspectos básicos do modelo clássico de interpretação do presidencialismo na América Latina e de suas conseqüências para a eficácia do governo e a estabilidade da democracia.

Com base em uma pesquisa comparativa sobre países com presidentes eleitos diretamente, Shugart e Carey constroem uma tipologia que distingue três sistemas presidenciais.

O sistema presidencialista puro tem as seguintes características: o chefe do Executivo é eleito diretamente; os mandatos do Executivo e do Legislativo são fixos e não estão submetidos ao voto de confiança mútua; o Executivo eleito nomeia e dirige a composição do governo; o Executivo tem algum poder legislativo garantido constitucionalmente. Esta última característica do presidencialismo é vista pelos autores como forma de assegurar que o apoio popular por meio da eleição presidencial possa ser 
traduzido de fato na produção legal. A Venezuela seria o único país a não preencher esse critério, pois ali o presidente não tem poder de iniciar legislação nem de vetar (Shugart e Carey, 1992: 19-20).

O sistema premier-presidential caracteriza-se pela existência de um presidente eleito diretamente, e com consideráveis poderes, e de um primeiro-ministro e um gabinete sujeitos à confiança do parlamento desempenhando funções executivas (Shugart e Carey, 1992: 23). Essa definição corresponde exatamente à definição original de Duverger (1980) do sistema que ele denomina como semipresidencialismo. O exemplo mais conhecido desse sistema é o francês.

Por fim, o sistema president-parliamentary também caracteriza-se pela eleição direta do presidente, que nomeia e demite os ministros e tem um gabinete sujeito à confiança do parlamento, mas o presidente tem o poder de dissolver o parlamento ou de legislar, ou ainda ambos os poderes. Há, apenas, dois exemplos desse sistema na América Latina: o Peru (sob a Constituição de 1968), e o Equador (sob a Constituição de 1962).

O principal problema da classificação de Shugart e Carey é a incorporação dos poderes do presidente na definição dos diferentes sistemas presidenciais. Esse critério foi também adotado por Duverger em sua formulação original do semipresidencialismo nos anos 1970. A literatura mais recente, porém, exclui os poderes do presidente e define o semipresidencialismo apenas em função da coexistência de um presidente eleito para um mandato fixo e de um primeiro-ministro e um gabinete que são responsáveis perante o parlamento. Dessa forma, o semipresidencialismo é tratado como um tipo puro de sistema de governo, que coexiste com os outros dois tipos puros, o parlamentarismo e o presidencialismo (Elgin, 1999). Na realidade, a incorporação dos poderes do presidente como um traço definidor de diferentes sistemas presidenciais é inconsistente com a própria análise desenvolvida por Shugart e Carey, pois a principal contribuição do seu estudo é exatamente mostrar a grande variação existente nos poderes do presidente no interior de cada um desses tipos, especialmente no presidencialismo latino-americano.

Shugart e Carey distinguem dois tipos de poderes constitucionais: os poderes legislativos do presidente - que incluem poderes de veto total e parcial; de decreto; orçamentários; de iniciativa exclusiva de legislação; e de referendo - e os poderes de nomeação e demissão do gabinete e de dissolução da assembléia. No interior de cada um desses poderes, especificam dimensões que são mensuradas por meio de uma escala de 0 a 4. Considerando apenas os países da América Latina que se incluem na categoria de sistemas presidenciais puros (com exceção dos casos residuais mencionados acima), Shugart e Carey mostram que o país onde o presidente detém a maior soma de poderes legislativos é o Chile, com 12 pontos sob a Constituição de 1969 e 8 pontos nas Constituições de 
1891 e de 1925, seguido pela Colômbia, com 8 pontos, e pelo Brasil, com 7 pontos sob a Constituição de 1946 e 9 sob a Constituição de $1988 .{ }^{6}$ No outro extremo fica a Venezuela, onde o presidente é completamente destituído de poderes legislativos, não podendo enviar projeto de lei ou vetar legislação aprovada pelo Legislativo.

Com base nessa pesquisa, Shugart e Carey refutam as conclusões de Linz sobre os "perigos" do presidencialismo, afirmando que "nem todas as presidências nasceram iguais". Argumentam que as críticas de Linz não se aplicariam ao presidencialismo em geral, mas apenas "às presidências fortes". Países presidencialistas onde o presidente tem extensos poderes legislativos são "problemáticos", afirmam. Ao contrário, "assembléias mais fortes são associadas a governos mais efetivos e estáveis do que regimes com presidências fortes, porque as assembléias servem de arena para um contínuo ajustamento de conflitos". Para eles, "o problema da dualidade de legitimidade democrática, tão condenada pelos críticos do presidencialismo porque o sistema não contém um princípio democrático para resolver conflitos entre os poderes sobre quem melhor representa a vontade do eleitor, fica minimizado quando o Legislativo tem papel mais importante na legislação do que o presidente. Dessa forma, o presidencialismo com Congresso forte contém um princípio democrático para a resolução de conflitos entre poderes: o princípio de que a assembléia prevalece, sujeita a um compromisso com o presidente" (Carey e Shugart, 1992: 165).

Os autores partem do suposto de que presidentes institucionalmente fracos têm incentivos para negociar com o Legislativo. Presidentes com amplos poderes legislativos não têm incentivos para buscar a cooperação do Legislativo; ao contrário, são levados a agir unilateralmente e a usar seus poderes para impor sua vontade ao Legislativo. Por essa razão, países presidencialistas com presidente forte apresentam um padrão conflituoso de relações Executivo-Legislativo (Shugart e Carey, 1992: 37-38).

Por outro lado, Shugart e Carey, consideram, da mesma forma que Linz, que a tensão entre a política paroquial e a nacional é inerente ao presidencialismo por ser este um sistema que "elege diretamente um Executivo nacional". Esse problema não se colocaria no parlamentarismo, porque os grupos de legisladores representantes de distritos específicos precisam sustentar um governo e, por isso, estão dispostos a agir coletivamente e apoiar partidos programáticos e políticas nacionais. Apoiando-se no estudo de Cox (1987) sobre a emergência dos partidos na Inglaterra vitoriana, os autores sugerem que "a prática da dependência do governo da confiança da maioria parlamentar" deu origem à erosão do poder dos parlamentares individuais (backbenchers) (Shugart e Carey, 1992: 168-69). Para Cox, no entanto, a perda de poder dos parlamentares individuais resultou do crescente monopólio que o gabinete passou a ter sobre a agenda legislativa, 
ou seja, a perda de direitos parlamentares, que lhes afetou a capacidade de prover benefícios para as suas bases eleitorais, levou parlamentares britânicos a apoiar gabinetes responsáveis pela política nacional. Cox afirma que "o desenvolvimento de um eleitorado orientado pelo partido em meados do período vitoriano foi baseado principalmente na erosão prévia dos poderes dos parlamentares individuais (...). O parlamentar individual tornou-se insignificante na determinação das políticas públicas gerais ou locais, por volta de 1860, e os eleitores responderam a isso usando o seu voto para determinar o que importava: o controle partidário do Executivo. Dessa forma, a crescente disposição dos parlamentares de vincular suas campanhas à legenda partidária, alterando sua relação com o eleitorado, e o conseqüente foco do eleitorado no Executivo decorrem da centralização da autoridade legislativa no gabinete" (Cox, 1987: 136-37). Vale ressaltar que o controle da agenda legislativa e a centralização do processo decisório são independentes do sistema de governo.

Para Shugart e Carey, a possibilidade de minimizar a tensão entre política nacional e local no presidencialismo depende do sistema eleitoral, uma vez que o sistema de governo não garante o vínculo entre o Executivo e o Legislativo. Os autores não se referem à existência de maiorias parlamentares, ou seja, de uma distribuição de preferências que garanta a coincidência entre o presidente e o Congresso, mas às características do sistema de representação que determinam os incentivos dos políticos na arena eleitoral. Para eles, sistemas eleitorais que aumentam o poder das lideranças nacionais e, portanto, o valor da legenda partidária são os que contribuem para maior eficiência eleitoral, permitindo articular políticas nacionais (Shugart e Carey, 1992: 170-71). Por outro lado, sistemas eleitorais que incentivam a competição intrapartidária - isto é, em que membros de um mesmo partido competem com os demais por votos pessoais - são os mais ineficientes eleitoralmente.

Tendo em vista, portanto, que presidentes fracos têm incentivos para negociar e que o controle que as lideranças dos partidos exercem sobre seus membros gera partidos programáticos, os autores concluem que "o meio mais promissor de aumentar a eficiência é aumentar a força dos partidos e, simultaneamente, diminuir a força da presidência" (Shugart e Carey, 1992: 174). Já o segredo da ineficiência é a combinação de presidência forte com partidos fracos.

A análise empírica de Shugart e Carey, que compara cinco indicadores de força das lideranças partidárias com a força do presidente em onze países da América Latina e nos Estados Unidos e Filipinas, mostra resultados apenas parcialmente consistentes com os pressupostos teóricos do modelo apresentado. Como reconhecem os autores, dois países se destacam como outliers: os Estados Unidos, com presidente e partidos fracos, e o Equador, com presidente e partidos fortes. Os autores 
apresentam explicações ad hoc para justificar esses resultados, mas desconsideram a mais clara evidência contra o modelo utilizado: a Argentina, país com alta instabilidade no período, apesar de apresentar as características institucionais requeridas - presidente fraco e partidos fortes. Os dois grupos polares apóiam o modelo: o primeiro, com partidos fortes e presidentes fracos, que inclui a Costa Rica, a Venezuela e a República Dominicana, e o segundo, que combina Executivos fortes e partidos fracos, incluindo o Brasil, o Chile e a Colômbia.

Para os autores, os sistemas ineficientes têm origem no interesse de parlamentares com bases regionais e laços pessoais com o seu eleitorado em delegar autoridade ao Executivo, permitindo que o governo implemente políticas nacionais sem se comprometer com os efeitos dessas políticas sobre suas bases eleitorais. Ao mesmo tempo os parlamentares preservam sua autonomia, ou seja, ficam livres para servir suas clientelas eleitorais por meio da transferência de recursos orçamentários e políticas de cunho particularista. O resultado disso é um considerável grau de dependência mútua. Em um Congresso descentralizado, há poucas chances de que cada parlamentar tenha acesso a recursos, mas a perspectiva de sucesso aumenta, tendo em vista a possibilidade de fazer acordos com uma figura central poderosa. Para o presidente, por sua vez, tais acordos são fundamentais para a obtenção de apoio legislativo e, assim, recursos serão alocados de forma a alcançar o maior retorno eleitoral (Shugart e Carey, 1992: 187-90).

O modelo conflituoso de relação entre Legislativo e Executivo fortes apóia-se no suposto de que os poderes do presidente vão ser usados contra a maioria parlamentar. Vale ressaltar, porém, que ao falar em Presidência forte os autores referem-se a poderes constitucionalmente garantidos: a base empírica em que se apóiam são as Constituições desses países. Isso exclui, portanto, a força que deriva de meios extra ou paraconstitucionais. Nesse sentido, esses poderes são claramente limitados pela maioria partidária no Legislativo. Poderes legislativos, inclusive de decreto com força de lei, como a medida provisória, não permitem que o Executivo passe por cima de maiorias partidárias.

A literatura, em geral, prevê maior uso desses instrumentos legislativos por presidentes sem maioria partidária no Congresso, ou seja, poderes institucionais são usados unilateralmente quando o Executivo é politicamente fraco. Sendo assim, o uso desses poderes aumenta quanto menor é o apoio partidário (Mainwaring e Shugart, 1997; Cox e Morgeenstern, 1998). Essas visões negligenciam o papel que esses instrumentos institucionais podem desempenhar nas mãos de presidentes que detêm maioria (ou quase maioria) partidária, especialmente em governos de coalizão. Os atributos desses poderes legislativos interagem 
com o poder partidário do presidente de formas não antecipadas por aqueles que os vêem exclusivamente como instrumentos para confrontar a resistência do Congresso.

Poderes legislativos do presidente, especialmente o de decreto com força de lei, podem ser também importantes meios para resolver problemas de "barganha horizontal" - entre o governo e sua base parlamentar -, e não apenas para resolver "conflitos verticais" - entre o Executivo e o Legislativo -, como enfatizado pela literatura. Seguindo a análise de Huber (1996) sobre o voto bloqueado, estabelecido pela Constituição francesa de 1958, é possível argumentar que tais mecanismos institucionais podem ser vistos não apenas como um meio de estabelecer uma relação hierárquica entre o Executivo e o Legislativo, que suprime a vontade da maioria e passa por cima do Legislativo, mas como um instrumento de proteção de maiorias partidárias em governos de coalizão. De acordo com o que Huber chama de hipótese da cobertura política, esses mecanismos institucionais podem ser usados para proteger a base majoritária do governo de debates ou votos sobre questões delicadas que são destacadas pela oposição minoritária, assim como para preservar acordos sobre questões específicas de políticas públicas feitos entre o governo e a sua base partidária. Dessa forma, o uso de medidas provisórias, por exemplo, pode não implicar conflito, mas ação concertada entre o governo e a maioria que o apóia no Congresso.

Apesar de sua importância para mostrar a diferenciação interna no presidencialismo, o trabalho de Shugart e Carey absorve da literatura anterior sobre o presidencialismo na América Latina o pressuposto comportamental do personalismo e do individualismo, tanto do presidente como do Congresso. Dessa forma, a análise por eles desenvolvida obscurece a importância dos poderes legislativos do presidente para a organização de sua base de apoio político e a coordenação do próprio governo.

\section{Considerações finais}

A aplicação de um modelo único de funcionamento dos diferentes sistemas de governo tem bloqueado o estudo comparativo sistemático dos fatores institucionais que afetam o funcionamento do governo e a natureza de suas políticas públicas nos diferentes sistemas de governo. A literatura comparada, especialmente os estudos de caso, mostram uma enorme variação na organização e no funcionamento dos governos no interior do parlamentarismo e do presidencialismo.

Ainda assim, as análises institucionais atribuem um grande peso explicativo aos fatores constitucionais distintivos de cada um desses sistemas de governo, ou seja, a separação ou a fusão de poderes, na 
determinação da capacidade de governo em definir e implementar políticas públicas. Mesmo quando um leque mais amplo de fatores é examinado, os estudos tendem a tratar separadamente os dois sistemas de governo, o que denota a importância atribuída às suas diferenças básicas.

Os estudos de caso e os modelos de análise mais recentes mostram a necessidade de ampliar o número e a natureza das variáveis institucionais a serem consideradas nos estudos comparativos. Mostram também que é preciso levar em consideração as relações entre diferentes tipos de mecanismos institucionais. Permanece, no entanto, como um desafio a comparação sistemática de um grande número de casos entre os dois sistemas de governo de traços institucionais específicos.

Os poderes de agenda do chefe do Executivo emergem, tanto nos estudos de caso quanto nos modelos de análise do parlamentarismo, quanto do presidencialismo como um mecanismo institucional que está presente nos dois sistemas de governo. No entanto, os estudos sistemáticos sobre os poderes de agenda também tratam separadamente os seus efeitos no parlamentarismo e no presidencialismo. É o caso do trabalho de Döring em 18 democracias européias e o do Alemán e Tsebelis nos países presidencialistas da América Latina, além do trabalho de Shugart e Carey analisado acima.

Mecanismos institucionais de agenda aumentam a probabilidade de sucesso nas estratégias controle do Executivo sobre o Legislativo, sobre os ministros e sobre a burocracia, ou seja, mecanismos institucionais de controle de agenda produzem os mesmos efeitos no presidencialismo e no parlamentarismo.

Em resumo, os poderes de agenda do Executivo independem do sistema de governo adotado e variam também ao longo da história de um mesmo país. ${ }^{7}$ Os poderes institucionais de agenda podem determinar o sucesso de estratégias de centralização do processo decisório e, dessa forma, produzir um impacto significativo sobre a capacidade do governo de coordenar sua própria estrutura interna - mantendo prioridades políticas, imprimindo unidade à sua política e exercendo efetiva coordenação de suas diversas atividades - e sobre sua capacidade de obter o apoio do Legislativo e a aquiescência da burocracia. 
* Este artigo é fruto do relatório escrito pela Prof. Argelina Maria Cheibub Figueiredo para o projeto de pesquisa encomendado pela ENAP em 2003, que estudou a importância da coordenação de ações governamentais no núcleo do poder Executivo. A autora agradece os comentários de Celina Souza, José Antônio Cheibub e Marcus Figueiredo.

1 Sintomaticamente, porém, alegando razões de simplicidade, tomam como base para a construção teórica que elaboram apenas os dois casos paradigmáticos de cada sistema: a Inglaterra e os Estados Unidos.

2 Esse mesmo modelo permeia, também, a análise de Laver e Shepsle (1999) sobre accountability no parlamentarismo.

3 Laver e Shepsle não tratam das diferenças entre os ministros. Nos estudos de caso de governos parlamentaristas, um conflito importante no interior do ministério dá-se entre os chamados "spending ministers" e os ministérios e/ou órgãos econômicos. Em um estudo clássico, Heclo e Wildavsky, tratando do processo decisório no gabinete e da relação entre esses dois tipos de ministros, mostram que o ministro da Fazenda, com o apoio do primeiro-ministro, é decisivo. Afirmam ironicamente que "essa maioria de dois geralmente é suficiente para determinar a maioria dos resultados” (1970: 162).

4 Na realidade, a crítica de Moe recai sobre uma das correntes neoinstitucionalistas dos estudos legislativos: a distributivista. Duas outras correntes, a informacional e a partidária, questionam essa interpretação, mas o distributivismo, senão como um todo, mas em seus mais importantes componentes, mostrou um forte poder de persistência nas interpretações gerais do sistema político americano. Para uma excelente resenha dessas três correntes, ver Limongi, 1994.

5 Ver Heclo 1977 e 1984.

6 A soma das seis dimensões dos poderes legislativos do presidente na escala proposta pode alcançar, no máximo, de 24 pontos. A mensuração adotada por Shugart e Carey apresenta alguns problemas que não serão discutidos aqui, mas que os levaram a classificar como igualmente fortes os poderes legislativos nas constituições brasileiras de 1946 e de 1988, quando, na verdade, elas são bastante diferentes nesse aspecto. Para dar uma idéia dessas diferenças, basta mencionar que a Constituição de 1988 institui a medida provisória, dá poderes exclusivos em matéria orçamentária e tributária ao Executivo, permite a delegação legislativa, dá poder de solicitar urgência a projetos introduzidos pelo presidente, além de dar ao presidente direito de apresentar emenda constitucional, poderes que inexistiam na Constituição de 1946. Para uma comparação sistemática dos poderes do presidente nas duas Constituições e dos efeitos que isto produz em termos de sucesso legislativo, dominância do executivo e padrão de coalizões legislativas, ver Figueiredo e Limongi, (2003).

7 Um dos mais influentes estudos que visa oferecer um modelo analítico que permita a comparação intersistemas de governo supõe que o Executivo detém o poder de agenda no parlamentarismo e fica nas mãos do Legislativo no presidencialismo (Tsebelis, 2002). 


\section{Referências bibliográficas}

AвERBACH, Joel D. e Rockman, Bert A. "Political and bureaucratic roles in public service reorganization." In Colin Campbel e B. Guy Peters (orgs.), Organizing governance, governing organizations. Pittsburgh: University of Pittsburgh Press, 1988.

Aberbach, Josel D., Robert A. Putham, and Bert A. Rockman. Bureaucrats and Politicians in Westem Democracies. Cambridge, MA: Harvard University Press, 1981.

AlemÁn, Eduardo e Tsebelis, George. "Agenda Control in Latin American Presidential Democracies". Paper prepared for delivery at the Annual Meeting of the American Political Science Association, August 29 to September 1 1 2002.

Avril, Pierre. Le Régime Politique de la V République. Paris: Librairie Générale de Droit et de Jurisprudence, 1964.

BadíA, Juan Fernando. Regímenes Políticos Actuales. Madrid: Tecnos, 1987.

BARON, David P. "A Spatial Bargaining Theory of Government Formation in Parliamentary Systems.” American Political Science Review 85:137-64, 1991.

"Government Formation and Endogenous Parties." American Political Science Review 87:34-47, 1993.

Baron, David P. e Daniel Diermeier. "Elections, Governments, and Parliaments in Proportional Representation Systems." Quarterly Journal of Economics 933-67, 2001.

Blondel, Jean e E. Drexel Godfrey, Jr. The Government of France. New York: Crowell, 1968.

BURKE, John P. Institutional Presidency - Organizing and Managing the White House from FDR to Clinton. Baltimore: The John Hopkins University Press, 2000.

Campbell, Colin e Margaret Jane Wyszomirski. "Introduction.” In: Colin Campbell e Margaret Jane Wyszomirski (orgs.). Executive Leadership in Anglo-American Systems. Pittsburgh: University of Pittsburgh Press, 1991.

CAmpBell, Colin. Governments Under Stress: Political Executives and Key Bureaucrats in Washington, London and Ottawa. Toronto: University of Toronto Press, 1983.

. Managing the Presidency: Carter, Reagan and the Search for Executive Harmony. Pittsburgh: University of Pittsburgh Press, 1986.

"The search for coordination and control: when and how are central agencies the answer?". In: Colin Campbel e B. Guy Peters (orgs.) Organizing governance, governing organizations. Pittsburgh: University of Pittsburgh Press, 1988.

CAmpbell, Collin e Wyszomirski, Margaret Jane (orgs.) Executive Leadership in AngloAmerican Systems. Pittsburgh: University of Pittsburgh Press, 1991.

Carey, John M, and MatThew Shugart (orgs.) Executive Decree Authority. Cambridge: Cambridge University Press, 1998.

CheIвuB, José Antônio. "Why do Parliamentary Democracies Last Longer Than Presidential Democracies?". Paper presented at the Conference on Consequences of Political Institutions, Duke University, April 5-7, 2002.

"Minority Governments, Deadlock Situations, and the Survival of Presidential Democracies". Comparative Political Studies, 35 (3), April, 2002a.

Cheibub, José Antônio e Przeworski, Adam. "Why are Presidential Democracies Unstable?". Manuscript, March, 2004. 
DehezA, Grace Ivana. "Gobiernos de Coalición en el Sistema Presidencial: América del Sur." Unpublished Doctoral Dissertation. Florence: European University Institute, 1997.

Dodd, Lawrence C. Coalitions in Parliamentary Government. Princeton: Princeton University Press, 1976.

DöRING, Herbert. "Time as a Scarce Resource: Government Control of the Agenda." In Herbert Döring (org.). Parliaments and Majority Rule in Western Europe. Frankfurt/New York: Campus/St. Martin's, 1995.

Duverger, Maurice. "A New Political System Model: Semi-Presidential Government." European Journal of Political Research 8:165-87, 1980.

La cohabitation des français. Paris: Presses Universitaries de France,

1987.

Eaton, Kent. "Parliamentarism and Presidentialism in the Policy Arena". Comparative Politics, October, 2000.

Edwards III, George C., Kessel, John H. e Rockman, Bert A. Researching the presidency: vital questions, new approaches. Pittisburgh: University of Pittisburg Press.

Edwards III, George C. At The Margins, Presidential Leadership of Congress. New Haven: Yale University Press, 1989.

Elgie, Robert. "The Politics of Semi-Presidentialism" and "Semi-Presidentialism and Comparative Institutional Engineering." In: Robert Elgie (org.), Semi-Presidentialism in Europe. Oxford: Oxford University Press, 1999. . "Cohabitation': Divided Government French-Style.” In: Robert

Elgie (org.), Divided Government in Comparative Perspective. Oxford: Oxford University Press, 2001.

Epstein, David, and Sharyn O'Halloran. Delegating Powers: A Transaction Cost Politics Approach to Policy Making under Separate Powers. New York: Cambridge, 1999.

FIORINA, Morris. Divided Government. New York: Macmillan, 1992.

Gallagher, Michael, Michael Laver, and Peter Mair. Representative Government in Western Europe. New York: Mc Graw Hill, 1992.

Haggard, Stephan e Mathew D. McCubbins (orgs.). Presidents, Parliaments, and Policy. New York: Cambridge University Press, 2001.

Hansen, Michel, and Charles H. Levine. "The Centralization-Decentralization Tug-ofWar in the New Executive Branch.” In: Colin Campbell e B. Guy Peters (orgs.). Organizing Governance: Governing Organizations. Pittsburgh: University of Pittsburgh Press, 1988. HaRgrove, Erwin C. "Presidential Personality and Leadership Style." In: George Edwards, John Kessel e Bert A. Rockman (orgs). Researching the Presidency: Vital Questions, New Approaches. Pittsburgh: University of Pittsburgh Press, 1993.

HeClo, Hugh e Aaron Wildavsky. The Private Government of Public Money: Community and Policy inside British Politics. London: Macmillan, 1974.

HeClo, Hugh, and Lester M. Salamon (orgs.). The Illusion of Presidential Government. Boulder, CO: Westview, 1981.

HeCLo, Hugh. A Government of Strangers: Executive Politics in Washington. Washington, DC: Brookings, 1977.

. "Executive budget making." In: Gregory B. Mills e John Palmer

(orgs.). Federal Budget Policy in the 1980s. Washington, DC, The Urban Institute, 1984. 
Heclo, Hugh. "In: Search of a Role: America's Higher Civil Service.” In: Ezra Suleiman (orgs). Bureaucrats and Policy Making: A Comparative Overview. New York: Holmes \& Meier, 1984.

Hennessy, Peter. "Demystifying Whitehall: the Great British Civil Service debate, 1980s style.” In: Colin Campbel e B. Guy Peters (orgs.). Organizing governance, governing organizations. Pittsburgh, University of Pittsburgh Press, 1988.

Henry, Laurin L. "The Presidency, executive staffing, and the federal bureaucracy." In: Aaron Wildavsky (ed.), The Presidency. Boston: Little, Brown, 1969.

Hess, Stephen. Organizing the Presidency. Washington, DC: Brookings, 1976.

Howell, William. Power Without Persuasion - The Politics of Direct PresidentialAction. Princeton: Princeton University Press, 2003.

Huber, John e Charles Shipan. Deliberate Discretion? The Institutional Foundations of Bureaucratic Autonomy. Cambridge: Cambridge Unversity Press, 2002.

Political Control of the State in Modern Democracies. Cambridge:

Cambridge University Press, 2004.

Hult, Karen M. "Strengthening presidencial decision-making capacity." Presidential Studies Quarterly 30, no 1 March, 2000.

Jones, George W. "Presidentialization in a Parliamentary System?” In: Colin Campbell e Margaret Jane Wyszomirski (ed.) Executive leadership in Anglo-American Systems, 1991.

Kernell, Samuel. Going Public: New Strategies of Presidential Leadership. Washington, DC: Congressional Quarterly, 1986.

KING, Anthony. "Modes of Executive-Legislative Relations: Great Britain, France, and West Germany.” Legislative Studies Quarterly 1:11-34, 1976.

"Foundations of power". In: George C. Edwards III, John H. Kessel e Bert Rockman A. (orgs.) Researching the presidency: vital questions, new approaches. Pittisburgh: University of Pittisburg Press, 1993.

. "Executives." In: Fred I. Greenstein e Nelson W. Polsby (orgs.).

Handbook of Political Science. Governmental Institutions And Processes. London: AddisonWesley Publishing Company, 1975.

Kingdom, John W. Agendas, Alternatives and Public Policies. New York: Harper Collins College, 1995.

Krause, George A. e Cohen, Jeffrey E. "Oportunity, constraints, and the development of the institutional presidency: the issuance of Executive Orders, 1939-96." The Journal of Politics. Vol. 62, n. 1. Feb., 2000.

KRISTINSSON, Gunnar Helgi. "Iceland.”'In: Robert Elgie (org). Semi-Presidentialism in Europe. Oxford: Oxford University Press, 1999.

Lanzaro, Jorge. Tipos De Presidencialismo y Coaliciones Politicas En América Latina. Buenos Aires: Clacso, 2001.

Lauvaux, Philippe. Parlamentarisme Rationalisé Et Stabilité Du Pouvoir Exécutif. Bruxelles: Bruylant, 1988.

LaVer, Michael e ShePsle, Kenneth A. "Cabinet Ministers and Government Formation in Parliamentary Democracies." In: Michael Laver Kenneth A. Shepsle (orgs.). Cabinet Ministers and Parliamentary Government. Cambridge: Cambridge Univeersity Press, 1995.

Laver, Michael e KenNEth A. Shepsle. "Divided Government:America is Not Exceptional." Governance 4:250-69, 1991.

University Press, 1996. . Making and Breaking Governments. Cambridge: Cambridge 
Laver, Michael e Kenneth A. Shepsle. "Government Accoutability in Parliamentary Democracy." In Adam Przeworski, Susan Stokes e Bernard Manin (orgs.), Democracy, Accountability and Representation. Cambridge, Cambridge University Press, 1999.

. "Coalitions and Cabinet Government." American Political Science Review 84:873-90, 1990.

LAVER, Michael, and Norman Schofield. Multiparty Government: The Politics of Coalition in Europe. Ann Arbor: The University of Michigan Press, 1990.

LAVER, Michael. Cabinet Ministers and Parliamentary Government. New York: Cambridge University Press, 1994.

Lowi, Theodore. "Presidential Power: Restoring the Balance," Political Science Quarterly 100,2: 185-213, 1985.

MAYER, Kenneth. "Executive Orders and Presidential Power," Journal of Politics. 61,2:445466, 1999.

With the Stroke of a Pen: Executive Orders and Presidential Power.

Princeton: Princeton University Press, 2001.

Metcalf, Lee Kendall. "Measuring Presidential Power." Comparative Political Studies vol.33 no.5: 660-85, 2000.

Moe, Terry e William Howell. "Unilateral Action and Presidential Power: A Theory." Presidential Studies Quarterly 29 no.4 (December), 1999b.

. "The Presidential Power of Unilateral Action." Journal of Law, Economics and Organization. Vol.15 n.1, 1999.

MoE, Terry M. "Bureaucrats, Legislators, and the Size of Government," American Political Science Review 77 (June 1983): pp. 297-332 (with Gary J. Miller). Reprinted in Andrew Levine, ed., The State and Its Critics (Hants, England: Edward Elgar, 1992), 1983.

."The New Economics of Organization." American Journal of Political Science 28 (November): pp.739-777. Reprinted in Problemi Di Amministrazione Pubblica Quadreno N.13 (1989), 1984.

. "The Politicized Presidency.” In John E. Chubb and Paul E. Peterson (orgs). The New Direction in American Politics. Washington, DC: Brookings, 1985.

" An Assessment of the Positive Theory of "Congressional Dominance"'. Legislative Studies Quarterly (November): pp. 475-520. Reprinted in Charles K. Rowley (org.). Public Choice Theory, Volume II (Hants, England: Edward Elgar, 1993). Also in Robert B. Ekelund, Jr. (org.) The Foundations of Regulatory Economics (Chiltenham, England: Edward Elgar, forthcoming), 1987.

. "The Politics of Bureaucratic Structure." In John E. Chubb and Paul E. Peterson (orgs). Can the Government Govern? (Washington, D.C.: The Brookings Institution): pp. 267-329, 1989.

. "Political Institutions: The Neglected Side of the Story," Journal of Law, Economics, and Organization 6 (1990): 213-254. Reprinted in Charles K. Rowley, Public Choice Theory (Hant, England: Edward Elgar), 1990.

. "Politics and the Theory of Organization," Journal of Law, Economics, and Organization 7: 106-129, 1991.

. "Presidents, Institutions, and Theory". In George C. Edwards III, John Kessel e Bert A. Rockman (orgs.). In Researching the Presidency: Vital Questions, New Approaches. Pittsburgh: University of Pittsburgh Press, 1993.

"The Presidency and the Bureaucracy: The Presidential Advantage." 
Moe, Terry M. "Control and Feedback in Economic Regulation: The Case of the NLRB." American Political Science Review 79 December, p. 1094-1116, 1985.

"The Positive Theory of Hierarchies." In: Herbert F. Weisberg (org.)

Political Science: The Science of Politics (Agathon Press), 1985.

. "The Positive Theory of Public Bureaucracy." In: Dennis Mueller (org.). Handbook of Public Choice. Oxford: Basil Blackwell, 1997.

."The Positive Theory of Public Bureaucracy." In: Perspective on Public choice. Cambridge: Cambridge University Press.

Moe, Terry M. e Gary J. Miller. "The Politicized Presidency”. In: John E. Chubb e Paul E. Peterson (orgs). The New Direction in American Politics. Washington, DC: Brookings., 1985.

Moe, Terry M. e Michael Caldwell. "The Institutional Foundations of Democratic Government: A Comparison of Presidential and Parliamentary Systems." Journal of Institutional and Theoretical Economics 150/1: 171-95, 1994.

Moe, Terry M. e William Howell. "The Presidential Power of Unilateral Action.” Journal of Law, Economics, and Organization 15 oㅡ 1 (April): 132-179, 1999a.

MulLer, Wolfgang C. "Models of Government and the Austrian Cabinet". In: Michael Laver e Kenneth A. Shepsle (orgs.). Cabinet Ministers and Parliamentary Government. Cambridge: Cambridge University Press, 1994.

MülLeR, Wolfgang e KAARE Strom. Coalition Governments in Western Europe. Oxford: Oxford University Press, 2000.

Neustadt, Richard E. "Approaches to staffing the presidency: notes on FDR and JFK." American Political Science Review 57: 855-62, 1963.

. "Staffing the presidency." In: Henry M. Jackson (ed.), The National

Security Council: Jackson Subcommittee Papers on Policy-Making at the Presidential Level. New York: Praeger, 1965a.

. "Politicians and bureaucrats." In David B. Truman (ed.), The Congress and American's Future. Englewood Cliffs, N.J.: Prentice-Hall, 1965b.

"Presidency and Legislation: The Growth of Central Clearance". American Political Science Review. 48, 3:641-671, 1954.

Presidential Power: The Politics of Leadership. New York: Wiley,

1960.

Presidential Power and Modern Presidents: The Politics of Leadership

from Roosevelt to Reagan. New York: Free Press, 1990.

Norton, Philip. The British Polity: Logman. New York, 1991.

OLSEN, Johan P. “Administrative reform and theories of organization.” In: Colin Campbel e B. Guy Peters (orgs.). Organizing governance, governing organizations. Pittsburgh, University of Pittsburgh Press, 1983.

Ragsdale, Lyn e John J. Theis III. "The Institutionalization of the American Presidency, 1924-92," American Journal of Political Science. 41, 4:1280-1318, 1997.

RagSDALE, Lyn. Vital Statistics on the Presidency. Washington, DC. Congressional Quarterly Inc. 1996.

REISCHAUER, Robert D. “The congressional budget process.” In: Gregory B. Mills e John Palmer (orgs.). Federal Budget Policy in the 1980s. Washington, DC: The Urban Institute, 1984.

Rockman, Bert A. The Leadership Question: The Presidency and the American System. New York: Praeger, 1984. 
Rose, Richard. "The growth of government organizations: do we count the number or weigh the programs?" In: Campbel, Colin e Peters, B. Guy (orgs.). Organizing governance, governing organizations. Pittsburgh: University of Pittsburgh Press, 1988.

$1: 393-414,1971$.

"The making of cabinet ministers." British Journal of Political Science.

."The presidency: a chief but not an executive". Presidential Studies

Quarterly, vol 7. no 2. p. 5-26, 1977.

Rose, Richard e Ezra Suleiman (orgs.). Presidents and Prime Ministers. Washington, DC: American Enterprise Institution, 1980.

Rudalevige, Andrew. Managing the President's Program-Presidential Leadership and Legislative Policy Formulation. Princeton: Princeton University Press, 2002.

. "The structure of leadership: information, organization, and presidential decision making". Paper presented at the Annual Meeting of the American Political Science Association, Boston, 2002.

SALA, Brian R. "In Search of the Administrative President: Presidential "Decree" Powers and Policy Implementation in the United States." In: Carey, John M, and Matthew Shugart (orgs.) 1998. Executive Decree Authority. Cambridge: Cambridge University Press, 1998.

SARTORI, Giovanni. Comparative Constitutional Engineering: An Inquiry into Structures, Incentives and Outcomes. New York: NYU Press, 1997.

Schlesinger, Arthur Meier. The Imperial Presidency Boston: Houghton Mifflin, 1974.

Shugart, Matthew e John Carey. Presidents and Assemblies. New York: Cambridge University Press, 1992.

Shugart, Matthew S., and Scott Mainwaring. "Presidentialism and Democracy in Latin America: Rethinking the Terms of the Debate." In: Scott Mainwaring and Matthew S. Shugart (org.). In Presidentialism and Democracy in Latin America. New York: Cambridge, 1997.

Strom, Kaare. "Party Goals and Government Performance in Parliamentary Democracies." American Political Science Review 79:738-54, 1985.

University Press, 1990b.

Suleiman, Ezra N. Politics, Power, and Bureaucracy in France: The Administrative Elite. Princeton, NJ: Princeton University Press, 1974.

"Presidential Government in France." In Richard Rose e Ezra N.

Suleiman (orgs.) Presidents and Prime Ministers. Washington, D.C.: American Enterprise Institute, 1980.

Sundquist, James L. (ed). Back to gridlock? Governance in Clinton Years. Washington D.C. Brookings Institution, 1995.

Constitutional Reform and Effective Government. Washington, D.C.:

Brookings, 1986.

"Needed: A Political Theory for the New Era of Coalition Government in the United States." Political Science Quarterly 103:613-635, 1988.

Thiвaut, Bernhard. "El Gobierno de la Democracia Presidencial: Argentina, Brasil, Chile y Uruguay en una Perspectiva Comparada.” In Dieter Nohlen e Mario Fernández (orgs). El Presidencialismo Renovado: Instituiciones y Cambio Político en América Latina. Caracas: Nueva Sciedad, 1998 
Thomas, Norman C. "Policy responses to economic stress and decline in Anglo Atlantic democracies". In: Colin Campbel e B. Guy Peters (orgs.). Organizing governance, governing organizations. Pittsburgh: University of Pittsburgh Press, 1988.

Tsebelis, George. Nested Games: Rational Choice in Comparative Politics. Berkeley: California Press, 1990.

Veto Players. Nova York: Russel Sage, 1990.

Weatherford, M. Stephen. "Responsiveness and Deliberation in Divided Government". British Journal of Political Science, 24 pp. 1-31, 1993.

WeAVER, Kent R. e Rockman, BertA. (orgs.).Do Institutions Matter? Government Capabilities in the United States and Abroad. Washington: The Brookings Institution, 1993.

Whittington, Keith E. e CARPENTER, Daniel P. "Executive Power and American Institutional Development." Perspectives on Politics, APSA, vol. 1. no 3, Sept., 2003. 
Revista do

Serviço

Público

Ano 55

Números 1 e 2

Jan-Jun 2004

Argelina Maria Cheibub

Figueiredo é

PhD em

Ciência Política pela Universidade de

Chicago;

professora

livre-docente

do Departamento de Ciência Política da

Unicamp;

Pesquisadora Sênior do Cebrap;

diretora do

Centro de

Estudos da

Metrópole,

Cepid-Fapesp/

Cebrap.

Contato: argelina@ uol.com.br

\section{Abstract}

\section{Resenha de estudos sobre o executivo \\ Argelina Maria Cheibub Figueiredo}

Este artigo é uma resenha da literatura sobre o Executivo que discute o impacto dos sistemas parlamentarista e presidencialista na capacidade governamental de formular e implementar políticas públicas. Ao longo do texto, busca-se identificar fatores que permitem ou bloqueiam o exercício de uma função coordenadora e unificadora de ações, analisando a relação entre os poderes Executivo e Legislativo, a estrutura do poder Executivo e as relações entre o Executivo político e a burocracia. Os estudos sobre parlamentarismo enfocam: importância dos partidos, papel dos ministros, extensão do poder do primeiro ministro e papel coletivo do gabinete. Já os trabalhos sobre presidencialismo vão de pesquisas sobre o Congresso norte-americano, envolvendo inferências estatísticas e análises baseadas na teoria institucional a estudos de caso sobre a American Politics (presidência e liderança). Apesar das diferenças entre parlamentarismo e presidencialismo, a literatura indica que mecanismos institucionais de controle de agenda produzem os mesmos efeitos nos dois sistemas.

\section{Reseña de estudios sobre el poder ejecutivo \\ Argelina Maria Cheibub Figueiredo}

Este artigo es una reseña de la literatura sobre el Poder Ejecutivo que discute el impacto de los sistemas parlamentarista y presidencialista sobre la capacidad gubernamental de formular y poner en marcha políticas públicas. A lo largo del texto, se busca identificar factores que permiten o bloquean el ejercicio de una función coordinadora y unificadora de acciones, analizando la relación entre los poderes Ejecutivo y Legislativo, la estructura del Poder Ejecutivo y las relaciones entre el Ejecutivo político y la burocracia. Los estudios sobre parlamentarismo enfocan: importancia de los partidos, papel de los ministros, extensión del poder del primer ministro y papel colectivo del gabinete. Los trabajos sobre presidencialismo van desde investigaciones sobre el Congreso norteamericano, incluyendo inferencias estadísticas y análisis basados en la teoría institucional hasta estudios de caso sobre American Politics (presidencia y liderazgo). A pesar de las diferencias entre parlamentarismo y presidencialismo, la literatura indica que mecanismos institucionales de control de agenda producen los mismos efectos en ambos sistemas.

\section{Study review about the executive}

\section{Argelina Maria Cheibub Figueiredo}

This article is a literary review about the Executive. It discusses the impact by the parliamentary and by the presidential systems on the government capacity for formulating and implementing public policies. The aim of the text is to identify factors which either allow or hinder the exercise of a function that coordinates and unifies actions, analyzing the relation between the Executive and the Legislative powers, the Executive power structure and the relations between the political Executive and the bureaucracy. The studies of the parliamentary structure focus on the importance of political parties, the role of the ministers, the extension of the Prime Minister's power, and the collective role of the Cabinet. The work on the presidential structure, on the other hand, ranges from research about the North American Congress, involving statistical inferences and analyses based on institutional theory, to case studies about the American Politics (presidency and leadership). Despite the differences between the parliamentary and the presidential structures, the literature suggests that institutional mechanisms for agenda control produce the same effect in both systems. 